\title{
Psychological theories of hippocampal function
}

\author{
NESTOR A. SCHMAЛUK \\ Center of Neurobehavioral Sciences \\ State University of New York, Binghamton, New York
}

\begin{abstract}
Theories and models of the hippocampus have typically linked this structure to various psychological processes, for example, internal inhibition, response inhibition, attentional shift, attentional "tuning out," recognition memory, long-term memory selection, contextual retrieval, spatial memory, working memory, and chunking. Predictions made from various models are contrasted with reproducible hippocampal lesion data obtained from various experimental paradigms: habituation to novelty, acquisition, extinction, discrimination reversal, spontaneous alternation, latent inhibition, blocking, overshadowing, passive avoidance, maze learning, working memory procedures, latent learning, retrograde spatial memory, and conditioned inhibition. No single model correctly predicts all the empirical evidence. It is suggested that the hippocampal function, rather than subserving a unitary psychological function, might be better described as a computational-representational activity.
\end{abstract}

The hippocampus has been described as a "beautifully organized structure of the brain in search of a function", (Swanson, Teyler, \& Thompson, 1981). Attempts to assign it a particular psychological function have been far from successful. A long list of psychological constructs has been linked to the hippocampus: internal inhibition, response inhibition, attentional shift, attentional "tuning out," recognition memory, short-term memory selection, contextual retrieval of information, spatial memory, and chunking. As O'Keefe (1979) has noted, the putative function of the hippocampus seems to correspond to the dominant psychological "climate" of the moment, ranging from the associationist approaches of the $60 \mathrm{~s}$ to the cognitive views of the 70 s.

Most theories of hippocampal function share the following features: (1) a unitary psychological function is assigned to the hippocampus; (2) different regions of the hippocampus collaborate in the same psychological function; (3) theories refer to an alleged generic mammalian hippocampus; (4) theories are verbal, often vague, and it is difficult to make precise predictions based on them, and (5) models are tested in terms of their ability to predict the behavioral results of hippocampal lesions (Olton, Becker, \& Handelman, 1979, p. 315). In addition to a psychological function, some models propose that the hippocampus performs certain computations on the information it receives.

This paper attempts to evaluate how well the psychological aspects of the theories predict animal experimen-

The author is a Fellow of the Consejo Nacional de Investigaciones Cientificas y Tecnicas de la Republica Argentina. He is indebted to R. L. Isaacson, J. W. Moore, and T. Dinan for their comments on the manuscript. The author's present address is: Department of Psychology, University of Massachusetts, Amherst, MA 01003. tal data. Predictions made by various models are compared with several behavioral effects that follow bilateral destruction of the hippocampus. Animals with hippocampal lesions show normal acquisition of classical conditioning (Schmaltz \& Theios, 1972) and instrumental learning (Schmaltz \& Isaacson, 1967), but they are relatively slow during extinction of classical conditioning (Niki, 1965) and instrumental learning (Jarrard, Isaacson, \& Wickelgren, 1964). They are deficient in acquiring a passive avoidance of an object they had previously learned to avoid (Kimble, Kirby, \& Stein, 1966), in reversing nonspatial discriminations (Douglas \& Pribram, 1966), and in habituating to novelty (Kimble, 1963). They behave like normals in latent learning (Kimble \& BreMiller, 1981) and in conditioned inhibition when training consisted of a stimulus, A, always reinforced, interspersed with stimuli A and B, always nonreinforced (Solomon, 1977). Spontaneous alternation, defined as the tendency for animals to alternate visits to the two nonrewarded boxes of a Tmaze, is impaired after hippocampal lesions (Douglas \& Isaacson, 1964). Hippocampectomized animals are also deficient in latent inhibition (McFarland, Kostas, \& Drew, 1978; Solomon \& Moore, 1975), blocking (Rickert, Bennet, Lane, \& French, 1978; Solomon, 1977), and overshadowing (Rickert, Lorden, Dawson, Smyly, \& Callahan, 1979; Schmajuk, Spear, \& Isaacson, 1983). Hippocampal lesions produce deficits in maze learning (see O'Keefe \& Nadel, 1978, for a review) and in spatial learning acquired previous to the lesion (Becker, Olton, Anderson, \& Breitinger, 1981; Sara, 1981). Working memory, defined as memory linked to nonpermanent aspects within an experiment, is affected after hippocampal lesions (Olton et al., 1979). Experiments that were specifically designed to test some of the models are also discussed in relation to the predictions. For the purpose 
of the review, models have been classified according to some common characteristics: attentional control, response inhibition, or memory mechanisms. This division is arbitrary, and most of the models have characteristics common to more than one class.

To foreshadow the results of our analysis, no single psychological theory can predict all the above-mentioned lesion data. It is suggested that the hippocampal function might be better described in terms of the computations the hippocampus carries out, rather than in terms of a psychological function.

\section{THEORIES INVOLVING ATTENTIONAL MECHANISMS}

\section{Grastyan et al., (1959): Inhibition of the Orienting Response to Irrelevant Stimuli}

Grastyan, Lissak, Madarasz, and Donhoffer (1959) proposed that the hippocampus inhibited the orienting response to nonsignificant stimuli. This function is correlated with its desynchronized electrical activity, such that when theta appears the inhibition disappears. Behavioral orienting reflex and hippocampal theta occur together. This view, correlating arousal or attention with the presence of theta rhythm, was first suggested by Green and Arduini (1954) and later adopted by Douglas and Pribram (1966).

If orienting responses cannot be inhibited after hippocampal lesions, tasks supposedly depending on their suppression will be affected. Habituation to novelty, which is defined as a weakening of the orienting response, would be impaired. Extinction would be retarded if it was assumed that it involved decreasing orientation towards the previously reinforced stimulus. Spontaneous alternation, maze learning, and discrimination reversal would be impaired if the animal continued to orient towards the nonreinforced cues. Latent inhibition, blocking, and overshadowing would be attenuated to the extent that they involved the suppression of orienting responses to irrelevant stimuli. Working memory procedures, which involve withholding orienting responses towards the depleted arms of a maze, would be impaired. However, animals with hippocampal lesions would behave like normals in acquisition, conditioned inhibition, latent learning, passive avoidance, and retrograde memory tasks, to the extent that inhibition of the orienting response is not involved in these tasks.

\section{Douglas and Pribram (1966), Kimble (1968), and Douglas (1972): Attentional Control and Internal Inhibition}

Douglas and Pribram (1966) proposed that the hippocampus excluded stimuli from attention through efferent control of sensory reception. This control would inhibit the reception of stimuli that have been associated with nonreinforcement, constituting a restatement of Pavlov's (1927) internal inhibition in attentional terms (Douglas, 1967).
Kimble (1968) proposed that the hippocampus was "part of the neural machinery necessary for the generation of a brain process that is functionally equivalent to Pavlovian internal inhibition." This function is brought about through the inhibition of "activating systems of the lower brain upon repeated presentations of the stimulus, enabling the organism to decouple its attention from one stimulus and shift its attention to new or more consequential environmental events" (p. 293). This decoupling would be faster when a previously reinforced stimulus was not followed by reinforcement.

In 1972, Douglas proposed another version of the Douglas and Pribram theory, in which the hippocampus was part of a system controlling learning and attention. The system, shown in Figure 2, is a modification of Sokolov's (1960) model for the control of orienting responses (Figure 1): analyzing and motivational systems in Douglas's model correspond roughly to the modeling and activating systems in Sokolov's model, respectively.

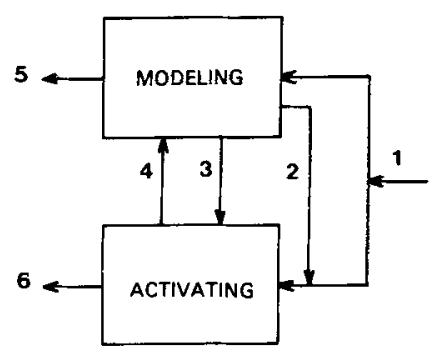

Figure 1. Sokolov's model. (1) Sensory inputs. (2) Inhibition of the activating system. (3) Excitation on the activating system. (4) Excitation on the modeling system. (5) Specific responses, innate or learned. (6) Orienting responses.

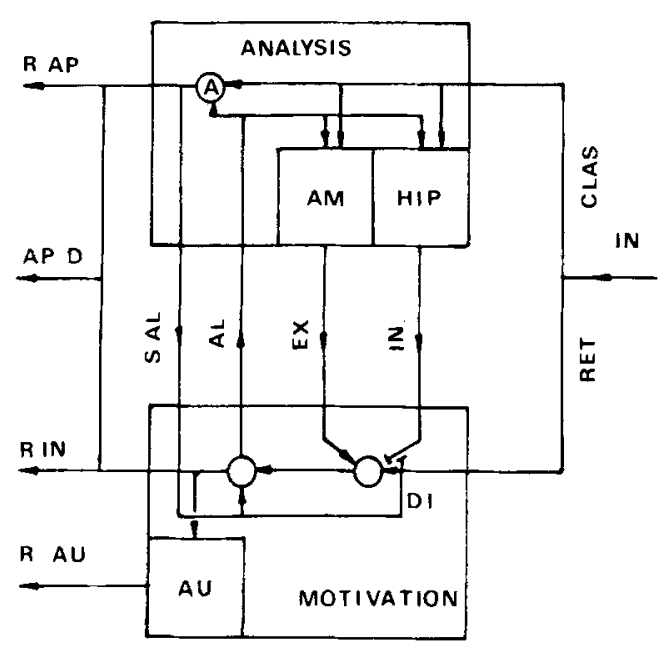

Figure 2. Douglas's model. IN, sensory inputs; CLAS, classical pathway; RET, reticular pathway; $A$, associations; AM, amygdala; HP, hippocampus; EX, excitation; $\mathbf{I N}$, inhibition; $A L$, arousal; S.AL., self-arousal; DI, disinhibition; $A U$, autonomic and endocrine systems; $\mathbf{R}$.AP, learned responses; AP.D, dynamic learning; R.IN, initial responses; R.AU., autonomic and endocrine responses. 
In Douglas's (1972) model, the analyzing system includes the neocortex, the nonreticular thalamic nuclei, the amygdala, and the hippocampus. The motivational system includes the reticular formation, hypothalamus, and reticular thalamus. The function of the analyzing system is to analyze sensory inputs and to form associations that are performed under activation of the motivational system. The hippocampus correlates a stimulus with nonreinforcement, and it blocks any later activation of the motivational system by that stimulus, reducing its attentional priority.

The three models presented in this section are based on the idea of the hippocampus as "the organ of internal inhibition," and they all relate internal inhibition to an attentional mechanism. This mechanism decreases attention to nonreinforced stimuli in Douglas and Pribram's and Douglas's models, but shifts attention from one stimulus to another in Kimble's model.

Douglas and Pribram's (1966), Kimble's (1968), and Douglas's (1972) models predict deficits in tasks in which internal inhibition is assumed to be involved. Habituation to novel stimuli, extinction, conditioned inhibition, and discrimination reversal would be retarded because, in these cases, the presentation of the stimulus followed by nonreinforcement would not generate internal inhibition, and therefore a persistence of responding would appear. Spontaneous alternation can be explained in terms of the internal inhibition associated with the stimuli present in the nonrewarded arms that would induce normal animals to select an alternative arm on a subsequent trial. Impairment of internal inhibition would cause deficits in spontaneous alternation. A similar explanation can be offered for the deficits shown in maze learning, since the lesioned animals would persist in responding to nonrewarded arms for longer periods than would normals. Latent inhibition would be affected by hippocampal lesions, to the extent that preexposure to the CS with nonreinforcement would not generate internal inhibition. Absence of overshadowing after hippocampal lesions can also be predicted without referring to an attentional deficit if the procedure involves the presentation of $A$ and $B$ together in reinforced trials and $B$ alone in nonreinforced trails. Blocking would not be affected after the lesion of the hippocampus, because the added CS is never presented with nonreinforcement. As far as passive avoidance is considered to be mediated by internal inhibition, animals with hippocampal lesions would perform poorly in this task. No effects of hippocampal lesions are predicted for acquisition, latent learning, retrograde spatial memory, and working memory procedures, on the basis of these theories.

\section{Pribram and Isaacson (1975): "Fast-Time" Computation of the Outcomes of a Response}

Pribram and Isaacson (1975) proposed that the hippocampus computes in "fast time," that is, in advance, the probability that a consummatory behavior will proceed to its completion. If the probability is high, then the animal does not change its behavior. If it is low, say be- cause some novelty has been detected, a behavioral shift becomes manifest (Pribram \& Isaacson, 1975, p. 433).

Pribram and Isaacson (1975) referred to the Sutherland and Mackintosh (1971) model of discrimination learning to point out that behavioral shifts involve both attentional and response factors. According to Pribram and Isaacson, the hippocampus acts on the amygdala to produce attentional changes and on the basal ganglia and nigrostriatal system to produce response changes (Figure 3 ).

Pribram and Isaacson's model predicts that animals with hippocampal lesions would show deficits in situations that require shifts in behavior, because neither attention nor responses can be modified once the consummatory behavior is established. From this perspective, acquisition, habituation, spontaneous alternation, maze learning, conditioned inhibition, and latent learning would not be affected because they do not involve behavioral shifts. Extinction would be impaired since once the behavior is acquired animals would have difficulties in shifting it. In the first phase of a discrimination reversal situation, animals learn to attend to a particular dimension and to associate it with the appropiate response. The reversal phase would be impaired if the lesioned animals could not shift their responses. Passive avoidance would be affected if the method involved an initial phase of positive reinforcement and a second phase of negative reinforcement, since animals would be unable to shift their responses from approach to avoid. Lesioned animals would show deficits in working memory procedures as long as they could not shift their attention away from depleted arms of the maze. Latent inhibition is explained in Sutherland and Mackintosh's model in terms of a decreased attention to a stimulus not followed by reinforcement. These changes in attention are allowed in Pribram and Isaacson's model as long as they precede the acquisition of the consummatory behavior. The model, therefore, predicts no effect of the hippocampal lesion of latent inhibition. On the second stage of blocking, normal animals would direct their attention to the CS presented on the first stage, decreasing the association between the second stimulus and the US. Since attention towards the first CS cannot be shifted, learning about the second CS would be even more reduced in lesioned animals than in normal animals, accentuating the blocking effect. Overshadowing would appear in normal animals because attention would be directed to the

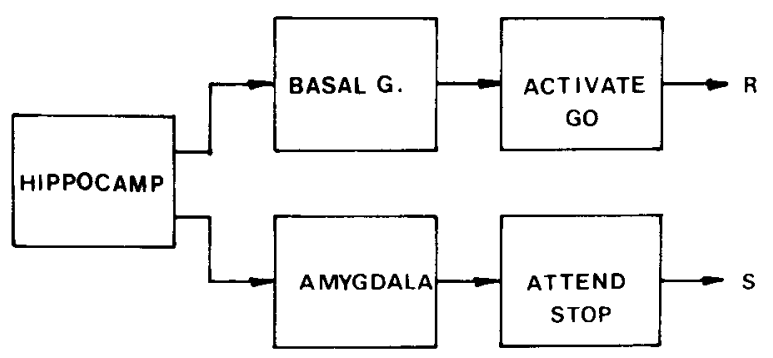

Figure 3. Pribram and Isaacson's model. R, activated response; S, attended stimulus. 
more salient stimulus while being shifted away from the less salient one, and this would reduce learning about the less salient stimulus. If attention could not be shifted away from the less salient stimulus, overshadowing would be affected in the hippocampal lesioned animals. According to the model, no impairments would appear in spatial memory established prior to hippocampal lesions.

\section{Solomon (1979): Temporal Map}

Solomon and Moore (1975) found that latent inhibition was absent after hippocampal lesions. Moreover, they found that hippocampectomy attenuated the blocking effect (Rickert et al., 1978; Solomon, 1977) and caused the absence of overshadowing (Rickert et al., 1979). In 1978, Berger, Alger, and Thompson found that unit activity recordings from the dorsal hippocampus seemed to form a temporal model of the response of the nictitating membrane in the rabbit during acquisition of classical conditioning. Based on the above evidence, Solomon (1979) suggested that, among a variety of other functions, the hippocampus could participate in the formation of a "temporal map" (another function would be a spatial map; see O'Keefe \& Nadel, 1978, in this review). This temporal map consists in the registration of the temporal sequence of events (CS and US), ignoring or eliminating irrelevant stimuli. Moore's (1979, see below) and Solomon's (1979) views are closely related to Douglas's (1972) model, but, although for Douglas the hippocampus attenuates the reception of nonreinforced stimuli, for Solomon and Moore it attenuates the reception of irrelevant stimuli.

Solomon hypothesized that after hippocampal lesions, irrelevant stimuli would not be ignored, and that, therefore, those processes in which this function is supposed to participate would be affected. These would be the cases of: habituation, because stimuli not followed by reinforcement should be ignored; extinction, because previously rewarded stimuli should be ignored and the S-R association should be weakened; spontaneous alternation, because stimuli present in a nonreinforced arm of the T-maze should be ignored; discrimination reversal, because previously reinforced stimuli should be ignored and new S-R associations should be built up; latent inhibition, because nonreinforced stimuli should be ignored; blocking, because a second, irrelevant, stimulus should be ignored; overshadowing, because the less relevant stimulus should be ignored; maze learning, because nonreinforced arms should be ignored; and passive avoidance, because a previously rewarded stimulus should be ignored. To the extent that stimulus "tuning out" is not involved in acquisition, conditioned inhibition, latent learning, retrograde spatial memory, and working memory procedures, these tasks would remain unaffected by the lesion.

\section{Moore (1979): Image of the Conditioned Response}

Moore (1979) proposed a neural model to explain how the "temporal map" would participate in the "tuning out" function of the hippocampus, particularly during the conditioning of the nictitating membrane response (Figure 4).

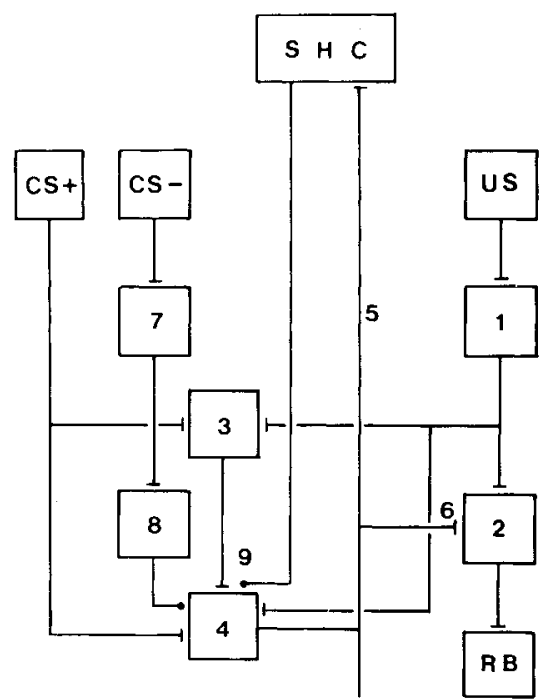

Figure 4. Moore's model. SHC, septohippocampal complex; RB, retractor bulbi; $\mathbf{T}$ endings, excitatory; point endings, inhibitory; numbers, see text.

The reticular formation neurons activate the muscle that causes the membrane to cover the eye. Blocks 1 and 2 in Figure 4 represent the polysynaptic arc activating the reflex, Blocks 3 and 4 represent neurons where the CS and the US converge, Block 5 represents the axons projecting the efferent copy of the CR, Block 6 represents the axons producing the $\mathrm{CR}$, Blocks 7 and 8 represent a conditioned inhibition chain, and Block 9 is a presynaptic (axo-axonic) inhibition to block the effect of the CS over the CR. Associations between CS and US would be produced at neurons 3 and 4 , through the increase of synaptic excitability at those postsynaptic receptor sites for the CS that are active concurrently with discharge firing caused by the US. The efference copy would reach the hippocampus before the motoneurons transform the information into an observable CR. As the hippocampus receives the efferent copy, it prevents new CSs from reaching the association neuron and decreases the presynaptic inhibition on the first CS.

Damage to the hippocampus would allow any new CS to be associated with the US, even when the US had already been associated (or more associated) with another CS present in the same trial, and this would explain blocking attenuation and absence of overshadowing. The model explains habituation and latent inhibition because when the $\mathrm{CR}$ is not produced, the hippocampus prevents the CS from exciting the associative neurons, and therefore, hippocampal damage would produce impairments in these tasks. Acquisition would be faster after hippocampal lesions, because the presynaptic inhibition was not present. In extinction and discrimination reversal, as the image of the CR began to fade because the CS was no longer paired with the US, the hippocampus would prevent the CS from reaching the motoneurons, and thus hippocampal lesions would retard these processes. Conditioned inhibition 
would not be affected. No predictions can be made for passive avoidance, spontaneous alternation, maze learning, latent learning, retrograde spatial memory, and working memory procedures, because these paradigms do not apply to nictitating membrane conditioning.

\section{Moore and Stickney (1980): \\ Attentional-Associative Networks in Real Time}

Pursuing a more precise expression for the "tuning out" function, considered in Moore's (1979) and Solomon's (1979) theories, Moore and Stickney (1980) proposed a mathematical model of the hippocampal function that departed from Mackintosh's (1975) attentional theory. Mackintosh's theory is represented by an equation that describes the variation of the associative strengths between the CS and US, $\Delta V=\alpha \cdot \mathrm{K} \cdot(\lambda-\mathrm{V})$, where $\alpha$ is the stimulus salience, $\mathrm{K}$ is the increment, and $\lambda$ the maximum value of associative intensity, $V$. Mackintosh proposed that alpha varies according to the following rules: (a) $\Delta \alpha_{\mathrm{A}}>0$ if $\left|\lambda-\mathrm{V}_{\mathrm{A}}\right|<\left|\lambda-\mathrm{V}_{\mathrm{X}}\right|$ and (b) $\Delta \alpha_{\mathrm{A}}<0$ if $\left|\lambda-V_{\mathrm{A}}\right| \geq\left|\lambda-V_{\mathrm{X}}\right|$. Moore and Stickney gave a quantitative formulation to these rules in the following terms: (1) $\Delta \alpha_{A}=C\left(1-\alpha_{A}\right)\left(V_{A}-V_{X}\right)$ and (2) $\Delta \alpha_{\mathrm{A}}=\mathrm{C}\left(\alpha_{\mathrm{A}}\right)\left(\nu_{\mathrm{A}}-\nu \mathrm{X}\right)$, where $\mathrm{C}, 0<\mathrm{C} \leq 1$. This variation of alpha would cause the animal to learn to ignore (tune out) stimuli poorly associated with reinforcement and to associate A faster with the US, if it predicted reinforcement better than the other stimuli. Latent inhibition is explained considering that stimuli $A(C S)$ and $X$ (context) have initial associative values of $V_{A} \neq$ $V_{X}=0$ and $\lambda=0$; during preexposure, it will be $\left|\lambda-V_{A}\right|=\left|\lambda-V_{X}\right|$, and therefore $\Delta \alpha_{A}<0$. Hence, stimulus $A$ loses salience and the animal ignores it. Blocking of stimulus B when the response was already conditioned to $A$, can be accounted for because $\left|\lambda-V_{A}\right|<\left|\lambda-V_{B}\right|$ and therefore $\Delta \alpha_{B}<0$. Overshadowing of stimulus $B$ by stimulus $A$, if $A$ is more salient or more contingent with the US than $B$, can be accounted for because $\left|\lambda-V_{A}\right|<\left|\lambda-V_{B}\right|$, and then $\Delta \alpha_{\mathrm{B}}<0$. Moore and Stickney proposed that the hippocampus carried out the above computations.

Hippocampal damage would prevent alpha from decreasing, or, in other words, would prevent stimuli from being "tuned out." As a consequence, latent learning, blocking, and overshadowing would be impaired. Moore and Stickney (1982) applied this model to goal tracking in spatial learning tasks, explaining in attentional terms maze learning deficits shown by hippocampal lesioned animals. One weakness of Mackintosh's (1975) model, that is, its omission of a mechanism for conditioned inhibition, represents an advantage for the Moore and Stickney model, because no deficit in conditioned inhibition is predicted after lesions of the hippocampus. The model predicts deficits in habituation, because alpha does not decrease after hippocampal lesions. In extinction, after a certain number of trials, alpha should decrease, since $\left(V_{A}-V_{X}\right)$ decreases in (1), causing extinction to proceed more slowly. If alpha did not decrease, hippocampal animals would have a faster extinction. Spontaneous alternation would be impaired because the animal would not decrease the alpha towards the stimuli present in the T-maze arms. According to the model, acquisition should proceed more slowly after hippocampal lesions because, as the alpha for the context $X$ cannot be reduced, the difference between $V_{A}$ and $V_{X}$ is less than that obtained by the normal animals, and hence alpha for $A$ will increase less in hippocampal lesioned animals during acquisition. In discrimination reversal, even if the extinction to the first rewarded stimuli was faster in hippocampal lesioned animals than in normals, for the reason mentioned above, acquisition of the association between the second stimulus and reward would be slower, and therefore the reversal would be retarded. Passive avoidance would be facilitated after hippocampal lesions because the alpha for the stimulus would remain high, and then extinction of the appetitive response and acquisition of the aversive response would be faster than in normal animals. No changes in latent learning, conditioned inhibition, retrograde spatial memory, and working memory are predicted on the basis of the model.

\section{Discussion}

In 1959, Grastyan et al. proposed the view, based on electroencephalographic data, that the hippocampus would be inhibiting the orienting response to irrelevant stimuli. Later on, this attentional control was proposed to underlie the psychological function of internal inhibition (Douglas, 1972; Douglas \& Pribram, 1966; Kimble, 1968). The internal inhibition hypotheses find serious difficulties in the fact that hippocampal ablations do not affect the formation of conditioned inhibition when training consisted of a stimulus $A$, always reinforced, interspersed with stimuli A and B, always nonreinforced (Solomon, 1977). However, when the CS and the context signaled the absence of the US and the context alone signaled its presence (Micco \& Schwartz, 1971), the development of conditioned inhibition was impaired. These findings provide support for the idea that context or spatial representations are affected by the lesion, as suggested by Hirsh (1980) and O'Keefe and Nadel (1978), but not the internal inhibition mechanism itself.

Moore (1979) and Solomon (1979) proposed a new attentional role for the hippocampus. In their models, the hippocampus controls the "tuning out" of nonrelevant stimuli instead of nonreinforced stimuli as Douglas proposed. A precise expression for this role was given by Moore and Stickney (1980), who proposed that the hippocampus was involved in the computation of the attentional variable alpha, as defined in Mackintosh's (1975) attentional theory.

\section{THEORIES INVOLVING RESPONSE INHIBITION MECHANISMS}

\section{Isaacson (1972): Inhibition of the \\ Ergotropic System}

According to Isaacson (1972), the limbic system can best be understood in relationship to the hypothalamus; 
therefore, any model of the limbic system must depend upon the model of the hypothalamus selected. Isaacson chose Hess's (1949) model of hypothalamic function, according to which the anterior regions of the hypothalamus are parasympathetic and trophotropic (related to energy conservation) and the posterior regions are sympathetic and ergotropic (related to energy mobilization). The ergotropic system is necessary to initiate and maintain every behavioral act. The trophotropic system is needed for terminating behaviors, rest, and sleep. The hippocampus inhibits the ergotropic systems of the hypothalamus, suppressing ongoing behavior activities, and this inhibition appears when the expectations about the environment are disconfirmed. The amygdala excites the ergotropic system, so animals with amygdalar lesions would show a trophotropic dominance.

Because hippocampal lesions would impair inhibition of behaviors initiated and maintained by the posterior hypothalamus, Isaacson's model predicts deficits in habituation, extinction, passive avoidance, maze learning, discrimination reversal, spontaneous alternation, and conditioned inhibition. Animals with hippocampal lesions would show deficits in working memory procedures because they would be unable to restrain visits to depleted arms in the radial maze. Situations in which inhibition of ongoing behaviors is presumably not involved, such as acquisition, latent learning, retrograde memory, latent inhibition, blocking, and overshadowing, would not be affected by the lesion.

\section{Altman, Brummer, and Bayer (1973): Response Braking}

Altman et al. (1973) suggested that the hippocampus participated in the inhibition ("braking") of responses in the aroused animal. According to the authors, their theory is similar to the concept of internal inhibition proposed by Kimble (1968). The use of the term "braking" instead of inhibition stresses the "unabated aroused state" (Altman et al., 1973, p. 583) of the activating system when hippocampal activity is absent. No reference to any attentional mechanism (see Kimble's or Douglas's model) is explicitly stated in Altman's model. Altman stressed similarities between lesioned and juvenile animals, an idea supported by Stanton and Amsel (1980), who found lack of negative contrast effect (also found in hippocampal lesioned animals) in young rats.

Two neural loops involve the hippocampus: (1) the direct septohippocampal (dentate gyrus and CA3 region), and (2) the indirect corticohippocampal (entorhinal cortex, CA1, mammillary bodies, anterior thalamic nuclei, and cingulate cortex). The inhibitory action occurs through facilitation of the septum (a response-braking system) and inhibition of the cingulate cortex (presumably a response-trigging system) (Altman et al., p. 578).

Altman's and Isaacson's models predict the same behavioral effects after hippocampal lesions, insofar as both involve the hippocampus in response inhibition.

\section{Gray, Feldon, Rawlins, Owen, and McNaughton} (1978): Inhibition of Nonrewarded Responses

According to Gray et al. (1978), the hippocampus inhibits nonrewarded responses while the animal determines its best behavioral strategy in changing circumstances (p. 286). The response inhibition system (Figure 5) responds to three types of inputs: (1) stimuli conditioned to punishment, (2) stimuli conditioned to frustration, and (3) novel stimuli. The output of the system produces: (1) inhibition of ongoing open behavior and of conditioned responses, (2) increased arousal, and (3) increased attention to the environment, especially to novel stimuli. When the best strategy is to continue with the original behavior, the hippocampus inhibits medial septal input acting over the lateral septum (Figure 5), precluding the inhibition of this behavior.

Gray et al. (1978) viewed their model as being similar to those of Douglas and Pribram (1966) and Kimble (1968, p. 294). However, in a later paper, Gray, Rawlins, and Feldon (1979) referred to Konorski's (1948) distinction between inhibition of classical and inhibition of instrumental responses: The first is Pavlov's internal inhibition, and the second is termed "response inhibition." According to Gray et al. (1979), although internal inhibition is preserved after hippocampal lesions, response inhibition is disrupted in passive avoidance and differential reinforcement of low rates (DRL).

With regard to hippocampal theta, Gray et al. (1978) suggested that there were several theta frequencies with different functional significances: (1) $7 \mathrm{cps}$ related to fixed action patterns, (2) $7.7 \mathrm{cps}$ related to behavioral inhibition, and (3) $8.5 \mathrm{cps}$ related to orientation towards the goal. The authors used Vinogradova's (1975) hypothesis that theta frequency quantifies information flow to explain the different frequency bands. Fixed action patterns are said to require low information flow (7 cps), environmental changes produce more sampling from the environment $(7.7 \mathrm{cps})$, and increased speed to the goal increases the need for more information processing $(8.5 \mathrm{cps})$.

Gray et al.'s (1978) model predicts two simultaneous effects of hippocampal destruction: reduced inhibition of behavior and decreased attention to novel stimuli when

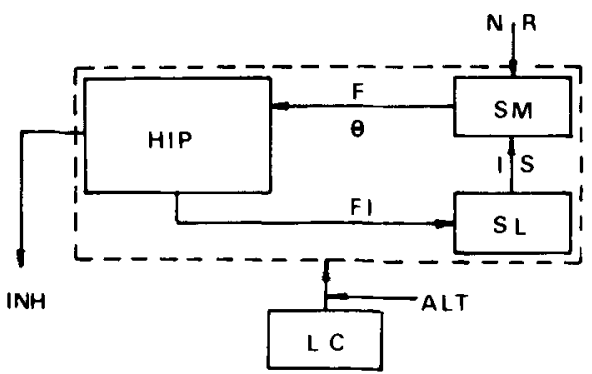

Figure 5. Gray's model. NR, nonreward; HIP, hippocampus; SM, medial septum; SL, lateral septum; LC, locus coeruleus; INH, inhibition of nonrewarded responses; F, fornix; $\theta$, theta rhythm; FI, fimbria; IS, intraseptal connection; ALT, ansiolitics. 
the animal is punished, frustrated, or presented with novelty. Predictions about the result of lesions on habituation to novel stimuli are difficult since, on the one hand, habituation would be enhanced by the decrease in attention to novel stimuli, but, on the other, it would be retarded because the animal could not inhibit its responses towards the stimuli. Extinction would be impaired because the animal would not be able to inhibit its responses to the previously rewarded stimulus, as would discrimination reversal, because extinction is retarded and, in addition, the animal would be slow to attend to the new stimulus. Spontaneous alternation would be impaired because of the failure in inhibiting responses to the nonrewarded arm of the maze; in addition, it would be difficult for the animal to attend to the alternative arm. Deficits in passive avoidance are predicted in terms of the inability to inhibit responses, and deficits in maze learning and working memory procedures are predicted in terms of the inability to inhibit visits to nonrewarded or depleted arms. Acquisition, latent learning, latent inhibition, blocking, overshadowing, and retrograde memory would not be affected by the hippocampal lesion. Conditioned inhibition is specifically excluded from the deficits presented after hippocampal damage, because it would be mediated by internal inhibition, which is not affected by the lesion.

\section{Gray (1982): Response Inhibition and Comparator}

In 1982, Gray modified his 1978 theory, and the function of the hippocampus is now to compare actual with expected stimuli. If actual and expected stimuli are the same, then behavior is maintained; if there is a mismatch, or an aversive stimulus is predicted, then the hippocampus takes control of behavior, producing behavioral inhibition and increasing attention. The motor program in effect at the time of the mismatch detection is tagged so that, on future occasions, it will be executed more slowly and will increase analysis of environmental stimuli. Also, exploratory behavior is initiated in order to test new hypotheses about the mismatch.

A block diagram of the system is shown in Figure 6. Predictions depend on the present state of the world, intended step in the motor program, and the stored regularities about the world. Once made, the prediction is compared with the world, if information coming from the world and the predicted are matched, and the same world information is used to feed the generator of predictions. The generator of predictions also acts over the world to establish what stimulus should be attended to in order to verify the predictions.

The comparator is embodied in the anatomy of the brain in the following way. The subicular area compares the information coming from the world, via entorhinal cortex, CA3, and CA1, with the prediction generated in $\mathrm{Pa}$ pez's loop. The cingulate cortex is the generator of predictions, and the anteroventral thalamus is a point of access for stored environmental regularities. The information is
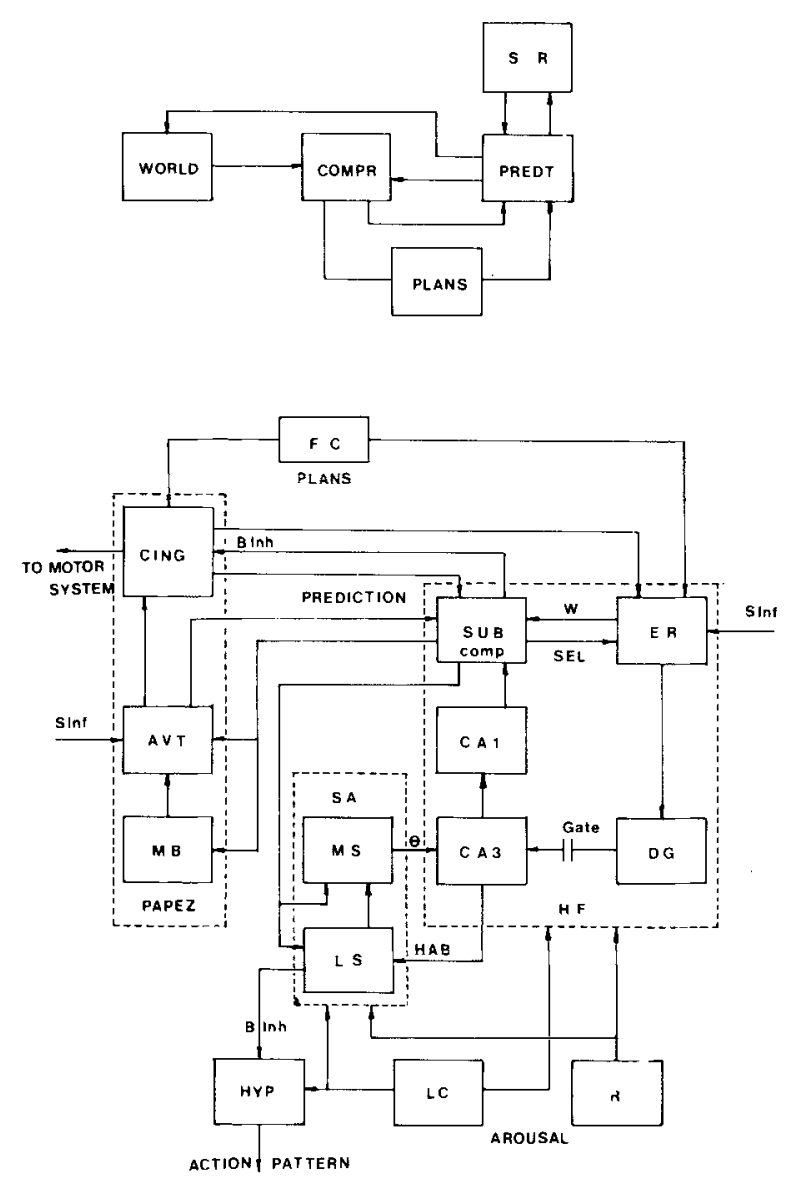

Figure 6. Gray's model. Upper diagram. SR, stored regularities; COMPR, comparator; PREDT, generator of predictions. Lower Diagram. FC, prefrontal cortex; CING, cingulate cortex; AVT, anteroventral thalamus; MB, mammilary bodies; SA, septal area; MS, medial septum; LS, lateral septum; HF, hippocampal formation; SUB, subicular area; DG, dentate gyrus; ER, entorhinal cortex; HYP, hypothalamus; LC, locus coeruleus; $R$, raphe nuclei; $B$. Inh, behavioral inhibition; $W$, world; SEL, selection; HAB, habituation; S.Inf, sensory information; COMP, comparator.

stored in neither the cingulate cortex nor the thalamus, but both activate its storage site within the temporal lobe. Plans about intended movements come from the prefrontal cortex. Selection of information of the world used to verify predictions is made by the comparator at the entorhinal cortex and the cingulate cortex (generator of predictions). The direct input to the subicular area from the entorhinal cortex describes the state of the world, whereas the input to the subicular area from the entorhinal cortex via the dentate, CA3, and CA1 selects the information to be compared at the subicular area. The way information is selected resembles that previously proposed by Kornhuber (1973, see below) and Vinogradova (1975).

The response inhibition aspects of the model are the same as in the Gray et al. (1978) model, so deficits would be present in extinction, discrimination reversal, spontaneous alternation, passive avoidance, working memory procedures, and maze learning. Gray's 1982 model, 
however, differs from the 1978 model in the mechanisms for attention; by introducing the Vinogradova circuit, the comparator processes only surprising or relevant stimuli. Habituation following hippocampal damage would be impaired because the animal would be processing irrelevant as well as relevant stimuli, and, for the same reason, latent inhibition, blocking, and overshadowing would be attenuated or absent. No deficits would be predicted in acquisition, conditioned inhibition, retrograde memory, and latent learning.

\section{Discussion}

Response inhibition hypotheses are a variation on the internal inhibition hypotheses, but without underlying attentional mechanisms. Unfortunately, for this class of models, rats with hippocampal lesions can inhibit responses in a go/no-go successive discrimination (Gaffan, 1973) and perform even better than controls in a go/nogo leverpressing (Means, Walker, \& Isaacson, 1970). Moreover, Olton (1972) found a response-suppression mechanism intact after hippocampal lesions, whereas a response-shift mechanism was impaired. Discrimination reversal would be impaired "not because of a failure to stop making the previous reinforced response, but of the inability to start making new reinforced responses." Recently, Berger and Orr (1983) suggested that hippocampectomized animals' failure in discrimination reversal could not be attributed to an increased resistance to extinction.

\section{THEORIES INVOLVING MEMORY}

\section{Adey (1966): Processing, Storing, and Recalling Information from Memory}

Adey (1966) suggested that hippocampal theta rhythm was associated with the active state of the structure when it was processing, storing, and recalling information to and from memory. This idea contrasts with Grastyan et al.'s (1959) view that theta appears when the hippocampus is inactive, but it coincides with Vinogradova's (1975) and Gray et al.'s (1978) views, which regard theta frequency as proportional to hippocampal activity. Adey's (1966) theory implies that if theta is blocked, recall of previously stored information should be difficult. This prediction has been supported by Bennet (1971), who found that pharmacological blocking of theta interfered with performance in a discriminatory task.

The model predicts deficits in acquisition, conditioned inhibition, maze learning, working memory, passive avoidance, retrograde spatial memory, and latent learning, because of the impossibility of storing and retrieving information following the lesion. Habituation and spontaneous alternation would be impaired because they both involve some degree of information storage. But, since acquisition is absent, the effect of the lesion on such behaviors as discrimination reversal, extinction, blocking, latent inhibition, and overshadowing cannot be assessed.

\section{Smythies (1966): Comparator Selecting Information to be Stored in the Long-Term Memory}

Smythies (1966) suggested that the hippocampus was necessary for storing the contents of short-term memory (located in the primary sensory cortex) in long-term memory (located in the temporal cortex). Smythies proposed that the hippocampus was a comparator (Figure 7), comparing input coming from the entorhinal cortex with input coming from the septum. If two similar patterns of inputs are received, pyramidal neurons fire and the information is stored into long-term memory. At the same time the reticular formation is activated in order to increase arousal.

The septal input can alternatively transmit: (1) information from the hypothalamus about the motivational state of the organism or (2) information already stored in the memory. The entorhinal input carries information about the environment. The hippocampus either: (1) selects information to be stored in the permanent memory, comparing it with the motivational state coming from the septum, or (2) classifies the sensory inputs as a function of past experience. In the case of temporal patterns, the dentate gyrus pathways and Schaffer's collaterals provide the delay circuits necessary to compare them.

Adey's view of the hippocampus as selecting information to be stored into long-term memory is incorporated in Kornhuber's (1973) model, and the view of the hippocampus as classifying information is closely related to Gaffan's (1972) recognition memory.

Lesions of the hippocampus would produce a total deficit in all tasks in which information was stored and retrieved from long-term memory (habituation, acquisition, conditioned inhibition, passive avoidance, maze learning, retrograde spatial memory, and latent learning). The absence of acquisition makes it impossible to assess the effects of the lesion on such behaviors as extinction, discrimination reversal, blocking, overshadowing, and latent inhibition. However, tasks in which only short-term memory is involved, such as working memory and spontaneous alternation, would be spared after hippocampal lesions.

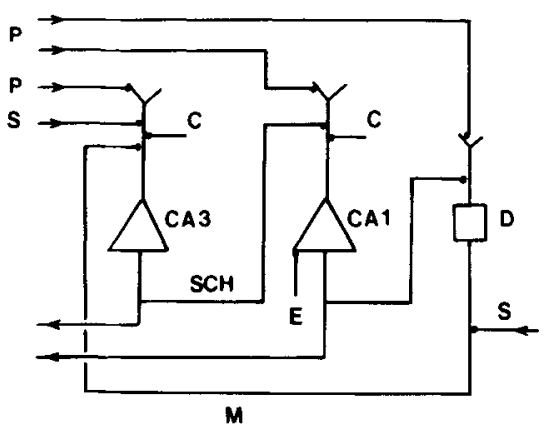

Figure 7. Smythies' model. Wiring of the hippacampus. C, commisural fibers; $P$, perforant path; $S$, septal input; $E$, entorhinal input; $D$, dentate; $S C H$, Schaeffer collaterals; $M$, mossy fibers. 


\section{Gaffan (1972): Novelty Detection}

Gaffan (1972) assumes two types of memory: associative and recognition. Associative memory implies storage and retrieval about two or more events that occur simultaneously, whereas recognition memory implies information about the novelty of a stimulus or a response. According to Gaffan, hippocampal lesions would affect only recognition memory, but he does not suggest that this information is stored in the hippocampus.

Several behavioral deficits can be explained in terms of failures in recognition memory. Maze learning deficits can be accounted for in terms of the lack of selection of the unfamiliar arm. Retardation of extinction is predicted because normal animals would respond faster to unfamiliar stimuli, and these responses would compete with the previously correct response. Passive avoidance would be impaired if the animals were slow in extinguishing the approach response to the object they should avoid. Deficits in discrimination reversal are explained in terms of deficits in extinction. Deficits in habituation can be predicted: because the novel stimuli remain novel; in spontaneous alternation, because the animal would not select the unfamiliar arm; in working memory procedures, to the extent that the already depleted arms are not recognized; and in latent inhibition, because the preexposed CS would remain novel. Blocking would be attenuated because the first-presented CS would not be discriminated from the second-presented CS, and therefore more associative strength would be gained by the second one. No deficit can be predicted for overshadowing, since both CSs would have the same difficulties in being recognized. Latent learning would be impaired because the already explored maze would not be recognized. To the extent that acquisition, conditioned inhibition, and established memory are mediated by the associative memory, they would not be impaired after hippocampal lesion.

\section{Kornhuber (1973): Selection of Information to be Stored in the Long-Term Memory}

According to Kornhuber (1973), the selection of information to be stored in long-term memory is carried out by the limbic system, which selects the contents of the short-term memory according to its biological value.

A diagram of the system (Figure 8a) shows an evaluation unit located between short- and long-term memory, and an attentional unit between the senses and short-term memory. The evaluation unit is activated by biological importance, and the attentional unit is activated by novelty. Both gates contribute to reduce the amount of information to be stored in long-term memory. The circuit involved in the selection of information (Figure $8 \mathrm{~b}$ ) includes the cingulate cortex, parahippocampal cortex, hippocampus, mammillary bodies, and anterior nuclei of the thalamus (p. 10). The motivation system, which includes the hypothalamus, amygdaloid complex, and orbital cortex, provides information to the selection unit by way of the septal region and cingulate cortex. Short- and

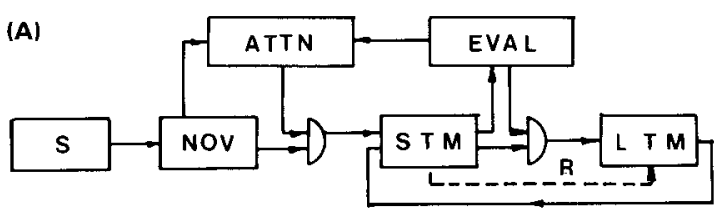

(B)

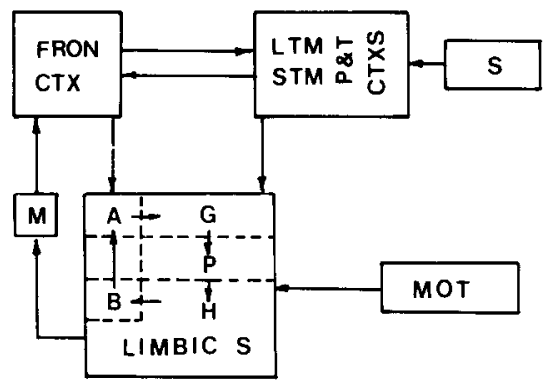

Figure 8. Kornhuber's model. (A) (upper diagram) S, stimuli; ATTN, attention; EVAL, evaluation; NOV, novelty; STM, shortterm memory; R, retrieval; LTM, long-term memory. (B) (lower diagram) FRON CTX, frontal cortex: P\&T CTXS, parietal and temporal cortexes; $M$, thalamic mediodorsal nuclei; $A$, thalamic anterior nuclei; G, gyrus cinguli; P, parahippocampus; H, hippocampus; B, mammilary bodies; MOT, motivation.

long-term memories are placed in different parts of the cortex, and the hippocampal output, which changes shortinto long-term memory, circulates through the medial dorsal thalamus and the frontal cortex.

According to the model, after the destruction of the hippocampus no information would be stored into long-term memory, resulting in deficits in habituation, acquisition, conditioned inhibition, passive avoidance, maze learning, and latent learning. If lesioned animals cannot learn, predictions about extinction, discrimination reversal, latent inhibition, blocking, and overshadowing are meaningless. Since short-term memory is not affected, processes such as spontaneous alternation and working memory might be considered to be unimpaired. No retrograde amnesia is predicted as far as information stored in memory is concerned and can be retrieved.

\section{Hirsh (1974): Contextual Retrieval of Information}

Hirsh (1974) regards the hippocampus as a part of a system that determines what information is retrieved from memory. Contextual retrieval is defined as "the retrieval of one item of stored information initiated by a cue which refers to the retrieved information." Two types of information storage are possible: on-line storage and parallel storage (Figure 9). Because on-line storage consists of a "functional connection between the neural elements sensitive to the stimulus and those responsible for producing the response"' (p. 422), the occurrence of a stimulus $S$ results in a response $\mathbf{R}$. Off-line storage refers to information stored off the performance line. When an item is retrieved, it is put onto the performance line. Perceptual systems become receptive to the stimulus described within 


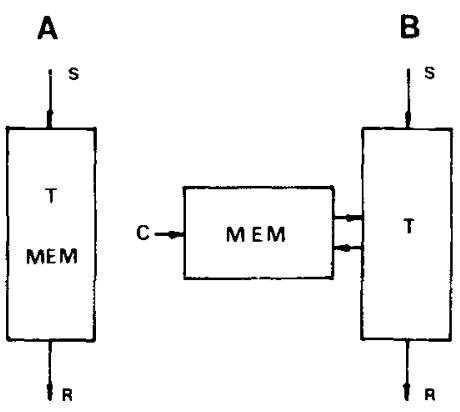

Figure 9. Hirsh's model. On-line (A) and parallel (B) information storage systems. T, transfer; MEM, memory; $S$, stimulus; $R$, response; $\mathrm{C}$, contextual cue.

the information, and motor systems are prepared to readily produce stored responses associated with that stimulus.

During learning in a parallel system, both the motivational state of the animal and some dimension of the problem determine the information to be retrieved from memory. The retrieved information controls behavior on a given trial. If reward is presented, the information would remain in control of behavior during future trials. If nonreinforcement follows, another item of information is retrieved and tested. These items are considered to be Krechevsky's (1932) "hypotheses learning," and learning occurs in few trials.

Learning in on-line systems is gradual and a cumulative function of reinforcement. Behaviors not correlated with reinforcement do not increase their association with incoming stimuli because the effects of reinforcements and nonreinforcements mutually cancel. During extinction, on-line systems would delete the stored information. Parallel systems would add a new contextual label indicating, without deleting it, that the stored information is no longer useful.

Lesions of the hippocampus produce deficits in contextual retrieval, and this implies abnormal behavior when there is conflict between previously acquired behavior and behavior to be acquired, because the old information must be cancelled instead of labeled. Failure to cancel old information would lead to interference of new learning. Deficits in passive avoidance, extinction, and discrimination reversal following hippocampal lesion are seen as a consequence of the difficulty in using the contextual label of the previously acquired information. Contextual retrieval would participate in maze learning, spontaneous alternation, and working memory procedures, as long as the behavior at choice points depended on previous decisions made by the animal. Therefore, hippocampal lesioned animals perform worse than normals in these tasks. Latent learning would be affected because an off-line system is needed to store the information that is not related to stimulus controlling behavior (Hirsh, 1974, p. 438). Habituation would be affected after hippocampal lesions because without the off-line mechanism the control of per- ceptual systems is impaired and previously presented stimuli would not be screened out (p. 431). No changes are predicted in acquisition because $S-R$ associations are unaffected after the lesion. Conditioned inhibition would be impaired only if training consisted of a CS and the context signaling the absence of the US and the context alone signaling its presence, but not if training consisted of the presentation of stimulus $A$, always reinforced, interspersed with stimuli A and B, always nonreinforced. Spatial retrograde amnesia can be explained in terms of the absence of contextual retrieval.

As pointed out previously, latent inhibition, blocking, and overshadowing are generally described as attentional phenomena, and can be seen as a consequence of a "screening out" function fulfilled by the hippocampus. Spear (1981) proposed that latent inhibition, blocking, and overshadowing could also be explained as retrieval phenomena, to the extent that the context would inhibit retrieval of information by stimuli that were irrelevant in that context. If contextual retrieval was absent, irrelevant stimuli would be able to retrieve its association with the response, and consequently, latent inhibition, blocking, and overshadowing would be absent.

Winocur and Olds (1978) observed that hippocampally lesioned animals showed impaired performance in a simultaneous discrimination procedure if tested in a different context from that of the original learning. If different contextual stimuli were used at the two phases of a discrimination reversal procedure, lesioned animals reduced their usual impairments. Winocur and Olds suggested that these data supported Hirsh's model; however, if hippocampal lesions produce a contextual retrieval deficit, Hirsh's (1974) theory predicts, in our view, no change in performance after changing context during testing, no matter how much the contextual stimuli are stressed. Attentional theories such as Moore and Stickney's (1980) provide a better explanation for an increased effect of the context on discrimination reversal during testing. In normal animals, context would be overshadowed by the conditioned stimulus, but this would not be so for hippocampal lesioned animals. Therefore, the context would be associated with the correct response. If context is changed, performance would be changed, and therefore performance would be impaired in a simultaneous discrimination task and facilitated when the discrimination was reversed.

\section{Vinogradova (1975): Control of Trace Formation}

Vinogradova (1975) proposed that the limbic system could be divided into two parts: (1) an informational portion and (2) a regulatory one. The informational portion includes the fascia dentata, CAl region, mammillary bodies, thalamic anterior nuclei, cingulate cortex, and entorhinal cortex (Figure 10). In these regions the quality of the sensory information is preserved. The fascia dentata generalizes and simplifies signals coming from the en- 
torhinal cortex and sends them to the CA3. When the CA3 detects novelty, it opens the information gate coming from the cortex to the CA1. The mammillary bodies perform a temporal analysis of information, being able to reproduce duration and rhythm of the stimuli through pacemaker neurons. The anterior thalamic nuclei suppress the interference noise (spontaneous discharge) during critical moments of information processing and storage. The cingulate cortex links the limbic system and associative cortical areas. Signals from the cingulate cortex are sent to $\mathrm{CA} 3$ and compared with those coming from the septal input, and their coordinated arrival makes $\mathrm{CA} 3$ cease its mismatch activity. The entorhinal cortex sends complex signals to the hippocampus both directly to CA1 and through the fascia dentata to CA3.

The regulatory portion of the limbic system includes the $C A 3$ region, lateral and medial septum, and reticular formation. In these regions, information about the quality of the sensory input is not present. Activity in CA3 presents habituation and dishabituation similar to the orienting response at the behavioral level. Its function is to assess novelty of the signal with respect to the trace, comparing the signals coming from the reticular formation and the associative areas of the neocortex. When novelty is detected, CA3 ceases to inhibit the activating reticular formation, the orienting response occurs, and cerebral activity increases in order to store more information in memory. Medial septal nuclei syncronize the signals from the reticular formation and the entorhinal cortex in order to compare them (by modulating the dendrites of the CA3) in discrete temporal intervals. Theta frequency is a measure of the flow of information to the hippocampus from the reticular formation. Lateral septal nuclei are the output of the CA3 to the reticular formation.

On the basis of the preceding descriptions, the limbic system operates as follows. When a signal coming from the reticuloseptal input to the CA3 does not coincide with that coming from the cortex, $\mathrm{CA} 3$ goes to a novelty state. In this state, inhibition over the reticular formation dis-

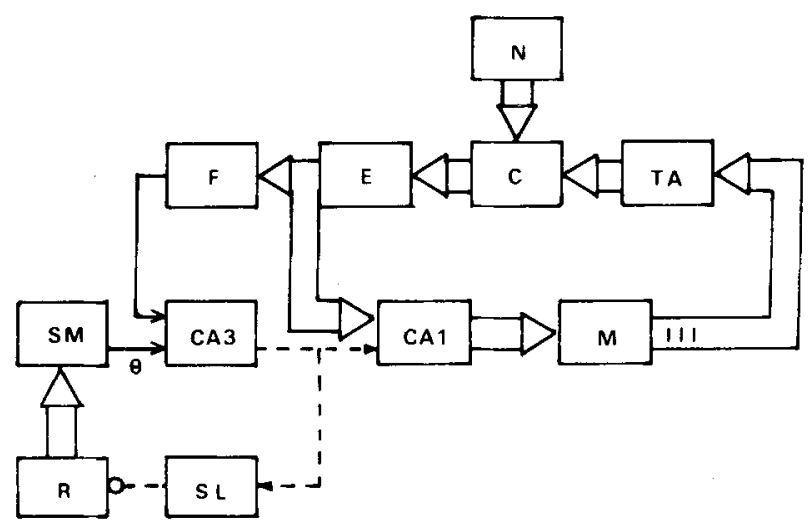

Figure 10. Vinogradova's model. $N$, neocortex; $C$, gyrus cinguli; E, entorhinal cortex; F, fascia dentata; SM, medial septum; $R$, reticular formation; SL, lateral septum; M, mammilary bodies; TA, thalamic anterior nuclei. appears and the reticular formation is activated until analysis of the new trace is carried out. According to Vinogradova (1975), her model closely resembles Kornhuber's (1973).

In Vinogradova's model, information is stored in longterm neocortical storage under the control of the regulatory system. After destruction of the hippocampus, no learning is possible, but no retrograde amnesia is predicted as far as the long-term storage is unaffected and retrieval is possible. Most of the predictions made by the model are the same as those made by Kornhuber's (1973) model, except that Vinogradova's also predicts deficits in spontaneous alternation as long as novelty cannot be detected.

\section{O'Keefe and Nadel (1978): Spatial Memory}

O'Keefe and Nadel (1978) proposed that the hippocampus was a spatial mapping system. They defined two ways of storing information about the environment: (1) spatial maps (defined as sets of connected places) and (2) routes (defined as lists of stimulus-response-stimulus). Information stored in spatial maps is referred to absolute spatial coordinates, whereas information stored as routes is referred to spatial coordinates relative to the animal's body axis. The model involves three anatomical areas of the hippocampal formation: (1) the fascia dentata, which converts input signals referred to relative spatial coordinates to a mapping system in absolute coordinates; (2) region CA3, which builds up a spatial map representing places and their connections; and (3) region CA1, which contains a novelty system that detects any change in the environment.

The fascia dentata receives input from entorhinal cortex, and its granule cells respond to multisensory stimuli occurring in a unique spatial configuration. For example, a granule cell would fire to a light in the North and a sound in the East (relative coordinates). Figure 11 shows that each entorhinal cell projects to a section of the hippocampus (lamella) at the same horizontal level and also projects collaterally over every neighboring section. Each lamella receives a different type of sensory input from a particular location in space, for example, light in North (O'Keefe \& Nadel, 1978, p. 224). The fascia dentata is proposed to act as a cross correlator such that each granule cell represents the conjunction of all stimuli received whenever the animal is in a certain place in space at a certain moment.

Region CA3 receives input from the fascia dentata through the mossy fibers and input from the septum through the fornix. The excitability of CA3 pyramids changes with theta rhythm, and the granule cells are fired synchronously by theta waves. In the CA3 region, the mapping machine (1) combines in a place representation all the stimuli received in the same place independently of the moment in which they have been received, and (2) connects these representations to information about distances and directions. Figure 12 shows a diagram of CA3 in which different pyramids are activated by different granule cells, each one representing places A, B, C, 


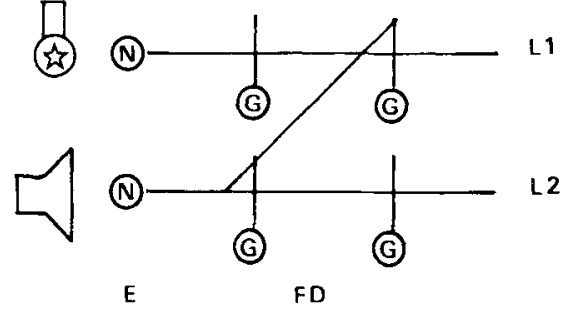

Figure 11. O'Keefe and Nadel's model. Fascia dentata diagram. $N$, neurons; $E$, entorhinal cortex; G, granule cells; $L N$, lamellas; FD, fascia dentata. Light in L1; sound in L2.

and D. Theta cycles excite different pyramidal cells at different times, and the inputs from fascia dentata are stored in different zones of the CA3 in an all-or-none fashion. Relationships between the represented places depend on the distance between them and not on the behavior employed to go from A to D. Neurons of the CA3 send information to: (1) lateral septum, which transforms maps into displacement coordinates, (2) motor circuits of the reticular formation, (3) CA1, and (4) fascia dentata, which coordinates the theta phase. If the animal desired to go from place A to place B (because there is food in place $B$ and the animal is hungry), theta generation would search for a program that activate the representation of A and B simultaneously (O'Keefe \& Nadel, 1978, p. 227).

Region CA1 produces an error signal whenever stimuli experienced previously in that part of the environment are no longer received. CA1 output activates exploring circuits of the reticular formation. Figure 13 shows a possible circuit for the CA1. As long as the theta cycle progresses, the excitable place on dendrites of CA1 pyramids moves and the same input excites different cells,

A
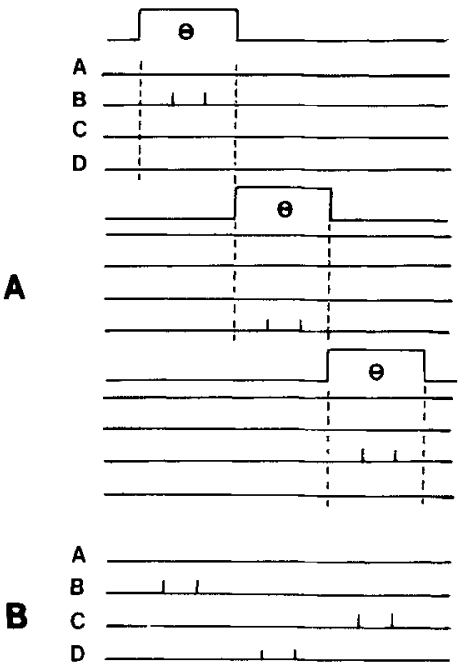

Figure 12. O'Keefe and Nadel's model, CA3 diagram. (A) Mapping system when the theta rhythm places the inputs (light, sound, etc.). (B) Environment representation after the animal went from A to $D$. depending on the moment of its arrival in relation to the theta cycle. If the received input does not coincide with the stored one, error units begin to fire. Theta rhythms would be generated: (1) when the animal made movements of exploration, and (2) when the animal searched in the hippocampal map for a motor program adequate to go from one place to another (intended movement). During exploration, movement control circuits of the posterior dorsomedial hypothalamus stimulates the medial septum, and this structure converts the motor programs into displacement coordinates. The theta frequency is proportional to the distance covered by the animal in the environment (O'Keefe \& Nadel, 1978, p. 226).

Hirsh (1980) supported O'Keefe and Nadel's (1978) model, suggesting that spatial maps were a particular variety of dimensional representation. According to Hirsh, the contextual retrieval model could explain any dimensional representation, including maps, as the interaction between contextual factors and stimuli

According to Kimble and Bremiller (1981), one prediction from O'Keefe and Nadel's model is that latent learning of spatial mazes should be absent in rats with hippocampal lesions. However, hippocampal lesioned rats showed significant latent learning after preexposure to the maze.

As mentioned before, Solomon (1980) suggested that the hippocampus participates in temporal mapping as well as in spatial mapping. This view is supported by the absence of latent inhibition (Solomon \& Moore, 1975) and the deficits in blocking (Solomon, 1977) following hippocampal lesions, tasks that do not seem to depend on spatial strategies. O'Keefe, Nadel, and Wilner (1979) argued, in response to Solomon, that classical conditioning involves spatial strategies because animals build up "place hypotheses" during conditioning, thereby defining the context in which it occurs. Latent inhibition is shown by normal animals because the stimulus is associated with that place and the place is a predictor of the absence of the US. However, O'Keefe et al. (1979) could not explain the absence of blocking after hippocampal lesions in terms of the spatial map theory. The theory is also unable to explain the absence of overshadowing.

Supporting O'Keefe and Nadel's (1978) theory, conditioned inhibition seems to be absent only when it is mediated through the place or context in which the animal is trained (Micco \& Schwartz, 1971), but not when it is mediated through a second CS (Solomon, 1977).

According to O'Keefe and Nadel's (1978) model, the consequences of hippocampal damage include the loss of novelty detection and of place learning. However, lesioned animals would still be able to acquire associations between stimuli and responses. Absence of a spatial map after hippocampal lesions would explain deficits in maze learning, spatial latent learning, and passive avoidance. Even if deficits in spatial discrimination reversal are predicted, the model does not predict impairments in nonspatial discrimination reversal. Impairments in latent in- 

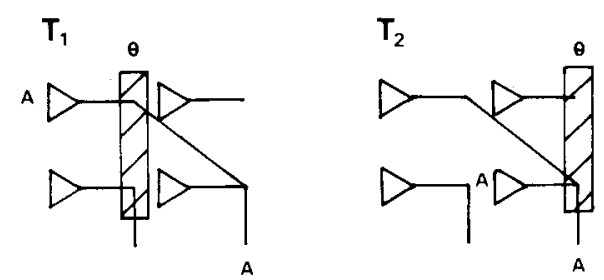

Figure 13. O'Keefe and Nadel's model. CA1 diagram. As theta rhythm moves, the same input $A$ excites different pyramids according to the moment, $\mathrm{T} 1$ or $\mathrm{T} 2$, of its arrival.

hibition are explained, as mentioned previously, in terms of the absence of learning about the place predicting the absence of the US. Spatial retrograde amnesia is predicted on the basis of damage to the locus of storage of spatial information. Habituation and spontaneous alternation deficits are explained because lesioned animals do not incorporate information about the environment into a mapping system. Deficits in extinction are predicted because the novelty-detecting system is lacking. Working memory would be impaired because the hippocampus would be involved in the representation of both reference and working spatial data.

\section{Olton, Becker, and Handelman (1979): Working Memory}

Olton et al. (1979) proposed that hippocampal function was related to working memory. They defined two types of memories: (1) reference memory, linked to aspects more or less permanent in the experiment, and (2) working memory, related to aspects of one trial within one experiment. Differences between them are: (1) Working memory differs from reference memory in requiring flexible, rather than fixed, S-R associations, whereas reference memory does not; (2) interference is greater in the working memory than in reference memory; and (3) working memory retains information about the temporal order of the stimuli.

To test their hypothesis against the spatial map view, Olton et al. (1979) designed an experiment in a radialarm maze in which rats learned (1) which the rewarded arms were, and (2) which arms had been visited in another trial and should not be revisited because they were depleted of food. After hippocampal lesions, rats had impaired reference (spatial map) and working memory, but the former recovered to normal levels.

Olton (1978) represented the functioning of working memory as the algorithm shown in Figure 14. Sensory input received at a particular arm of a radial maze is stored in a temporary register and compared with the information stored in working memory. A match between the sensory input and working memory indicates that the arm has been visited, and therefore the arm is not revisited. A mismatch produces a visit to that arm, and this visit is stored in working memory in order to prevent a new visit. When a trial begins, the temporary register is cleared, and so is the working memory.
A dispute between proponents of spatial memory and working memory resulted in several papers supporting both positions. Nadel and MacDonald (1980) supported O'Keefe and Nadel's (1978) model in an experiment in which rats were trained in two tasks: one involving place learning and the other, cue learning. Each involved both working and reference memory procedures. Hippocampal lesions affected reacquisition of place working and place reference memories, but not of cue learning, supporting O'Keefe and Nadel's view that the hippocampus is involved in spatial mapping of both reference and working data. Becker and Olton (1980) found that fimbriafornix lesioned rats could locate a goal from an unfamiliar starting point, suggesting that they had used a spatial-map strategy to solve the task. Becker et al. (1981) trained rats to discriminate between two objects on the basis of either location in the environment or the characteristics of the objects themselves. The rats received bilateral fornix-fimbria lesions after being trained. In the locationdiscrimination tests, the spatial mapping model received support from the finding that lesioned rats showed greater disruption in retention than did controls. However, lesioned rats could relearn the location discrimination and show in a transfer test that they had used a cognitive mapping strategy. In the object discrimination tests, the lesioned rats showed greater difficulty in reversal, a task not requiring spatial mapping. According to Becker et al. (1981), O'Keefe and Nadel's spatial-map model cannot explain either reacquisition of the location discrimination or the difficulty in the reversal of the object discrimination. On the other hand, Olton et al.'s (1979) working memory theory cannot explain why the lesions had a greater impact on location discrimination than on object discrimination. Supporting the spatial-map theory, Oades (1981) found that hippocampal lesions affected both spatial reference and spatial working memories on a 16-holeboard apparatus in which animals were trained to retrieve food pellets from 4 rewarded holes.

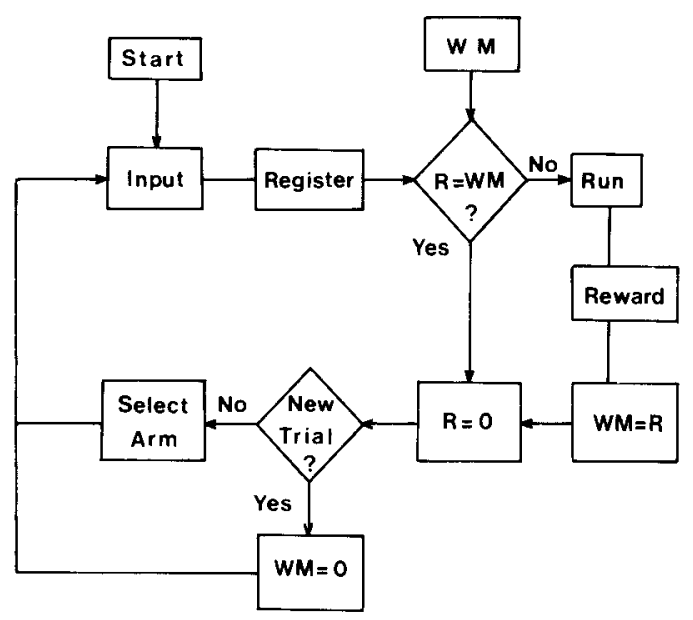

Figure 14. Olton's model. Flow diagram of the processes involving working memory, explaining the performance in the radial-arm maze. W.M., working memory; $R$, register. 
The working memory hypothesis predicts deficits in discrimination reversal in animals with hippocampal lesions because working memory would be lacking at the moment of the reversal. Spontaneous alternation is affected because the animal would not be able to remember which arm it had visited previously. Habituation would be affected because the animal could not remember what stimuli it had already attended to. Thomas, Brito, Stein, and Berko (1982) suggested that lesions in the hippocampal system affect maze learning because they impair the working memory necessary to build a cognitive map. Acquisition, extinction, latent inhibition, blocking, overshadowing, conditioned inhibition, passive avoidance, spatial retrograde memory, and latent learning would not be affected by hippocampal lesions to the extent that they do not involve working memory.

\section{Wickelgren (1979): Chunking and Consolidation}

Wickelgren (1979) defined two types of associative memory: (1) horizontal memory, in which all its elements (stimuli, response, ideas, etc.) have mutual associations and the activation of one element activates the whole set, and (2) vertical memory, in which every element is associated with another (higher) element representing the whole set. Learning in horizontal memory consists in the strengthening of associations among the elements of the set, and learning in vertical memory consists in the strengthening of the associations between each element of a set and a new element which is going to represent the entire set or chunk. Hippocampal lesions do not affect the S-R associations; instead, chunking and hierarchical cognitive learning are impaired. Wickelgren considered his ideas as related to Hirsh's (1974) view.

Wickelgren suggested that the temporal cortex had the capacity for chunking under the influence of the hippocampus, which activates nonbound elements (neurons) that are going to form a new chunk (consolidation or storage process). Cortical neurons are assumed to be partitioned into two sets: free and bound. Bound neurons are connected with other neurons, whereas free neurons are weakly connected to a large number of other neurons (free or bound) and can be chunked (Wickelgren, 1979, p. 56). When two bound neurons are activated simultaneously, there is one activated chain of free neurons connecting them, and since this chain has to compete with a possibly already existing bound-neurons chain, the hippocampus ensures that the free chain is maximally activated by inhibiting the bound or exciting the free neurons. By temporally contiguous activation, the two bound neurons and the free chain strengthen their connecting synapses (chunking). During retrieval, a different arousal system (perhaps the reticular formation) excites the bound neurons, and the chunked neuron is fired.

Animals with hippocampal lesions would be deficient in maze learning because they could not form a "cognitive map of what-leads-to-what expectancy nodes" (Wickelgren, 1979, p. 54). In tasks that maximize the interfer- ence between present and past learning, such as extinction, discrimination reversal, or passive avoidance (to avoid an object that previously had been approached), animals without hippocampus would be deficient because new chunking would not be possible. The model predicts that animals with hippocampal lesions would be deficient in latent learning (Wickelgren, 1979, p. 54) because they could not chunk spatial stimuli, but Kimble and Bremiller (1981) found that they are not. Also, retrograde amnesia (since the chunking is not completed) and anterograde amnesia (since no chunking can be accomplished) is predicted by Wickelgren's model. If one were to accept Spear's (1981) view that latent inhibition, blocking, and overshadowing were contextual retrieval deficits, these phenomena should be impaired after hippocampal lesions since no new "contextually dependent chunk nodes" could be formed (Wickelgren, 1979, P. 54). Deficits in working memory and spontaneous alternation would be explained, because without hippocampus it is not possible to form chunk nodes representing the concept "situation of arm A at time T." Habituation would be impaired because the animals would not be able to form chunks representing the idea of "context X." Acquisition and conditioned inhibition would not be impaired because they would be mediated by the horizontal associative memory.

\section{Discussion}

Models relating the hippocampus to memory received a great deal of attention as a consequence of anterograde amnesia found in humans with hippocampal lesions (Iversen, 1976). Among these models, those proposed by Adey (1966), Smythies (1966), Kornhuber (1973), and Vinogradova (1975) involved the hippocampus in storage of information into long-term memory. These models made the wrong prediction that acquisition would be absent after hippocampal lesions. Every model in this group, with exception of Olton et al.'s (1979), wrongly predicts latent learning impairments after hippocampal lesions. The Olton et al. (1979) model cannot deal with deficits shown in tasks involving attention.

Kornhuber's (1973) and Vinogradova's (1975) models cannot predict spatial retrograde amnesia as far as they are related only to storage processes. Instead, Adey (1966) and Smythies (1966) predict this deficit, because in their models the hippocampus is also involved in retrieval. Gaffan's (1972) and Hirsh's (1974) models predict retrograde amnesia as retrieval failures. For Gaffan (1972), retrieval of the associated memory is not possible because the CS is not recognized. For Hirsh (1974), retrieval is impaired because a contextual cue is missing in the retrieval code. For Wickelgren (1979), retrograde amnesia is due to a lack of chunking of the last stored information. And for O'Keefe and Nadel (1978), it is due to longterm spatial memory damage.

Hirsh's (1974), O'Keefe and Nadel (1978), and Wickelgren's (1979) models wrongly predict absence of latent learning. The problem in these models is that the hip- 
pocampus is not differentially involved in latent learning as opposed to maze learning. Therefore, the models predict, at the same time, impairments in latent learning, which conflict with the experimental data, and impairments in maze learning, which accord with experimental results.

\section{GENERAL DISCUSSION}

Every model seems to have difficulty in predicting some of the experimental findings. Theories involving internal inhibition, such as those proposed by Douglas and Pribram (1966), Kimble (1968), and Douglas (1972), are contradicted by the fact that hippocampal lesions do not always impair conditioned inhibition. Theories involving attentional mechanisms, such as those of Grastyan et al. (1959), Douglas (1972), Moore (1979), Solomon (1979), and Moore and Stickney (1980), can explain experiments such as latent inhibition, blocking, and overshadowing, which require a system's "tuning out" irrelevant information, rather than the attentional shift mechanism proposed by Smythies (1966), Kimble (1968), Pribram and Isaacson (1975), and Gray et al. (1978).

Theories involving response inhibition, for example, Isaacson's (1972), Altman et al.'s (1973), Gray et al.'s (1978), and Gray's (1982), have difficulty with the fact that animals with hippocampal lesions can inhibit responses. Neither Isaacson's nor Altman's models predict any attentional deficit.

Among theories involving memory processes, those of Kornhuber (1973) and Vinogradova (1975) do not predict retrograde amnesia; those predicting retrograde amnesia, such as Hirsh's (1974), O'Keefe and Nadel's (1978), and Wickelgren's (1979), also predict absence of latent learn- ing. Some theories wrongly predict complete anterograde amnesia (Adey's, 1966; Kornhuber's, 1973; Smythies's, 1966; Vinogradova's, 1975).

The theories making the most correct predictions about the experimental data are: Grastyan et al.'s (1959), Moore's (1979), and Solomon's (1979), in the attentional group, Gray's (1982), in the response inhibition group, and Hirsh's (1974) and Wickelgren's (1979), in the memory group. Some theories perform well due to their loose formulation, and in this sense Moore and Stickney's (1980) is the only one with the advantage of mathematical precision. It should be noticed that Moore's (1979) theory predicts correctly all the behaviors to which it is restricted. Table 1 shows the predictions made by the different models for different experimental situations, together with the experimental data obtained after hippocampal lesions. Even when some theories predict outcomes better than others, no theory can explain all the symptoms of the hippocampal syndrome.

As mentioned in the introduction, most theories are built upon the two basic assumptions that (1) there is a unitary psychological function performed by the hippocampus, and (2) lesion data is suitable for the assessment of the theories.

A unitary psychological function attributed to the hippocampus is one important aspect of every model considered: (1) Pavlov's (1927) internal inhibition, used by Douglas and Pribram (1966), Kimble (1968), and Douglas (1972); (2) Tolman's (1932) cognitive map, used by O'Keefe and Nadel (1978); (3) Konorski's (1948) response inhibition, used by Isaacson (1972), Altman et al. (1973), Gray et al. (1978), and Gray (1982); (4) Sutherland and Mackintosh's (1971) discrimination learning theory, used by Pribram and Isaacson (1975);

Table 1

Prediction Made by Each Model for the Outcomes of Some Experimental Paradigms After Hippocampal Lesions

\begin{tabular}{|c|c|c|c|c|c|c|c|c|c|c|c|c|c|c|c|c|c|c|c|c|}
\hline \multicolumn{2}{|l|}{ Experimental Data } & \multicolumn{19}{|c|}{ Theories } \\
\hline \multirow[b]{2}{*}{ Behaviors } & \multirow[b]{2}{*}{ 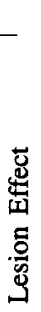 } & \multicolumn{6}{|c|}{ Attention } & \multicolumn{4}{|c|}{ Response Inhibition } & \multicolumn{9}{|c|}{ Memory } \\
\hline & & 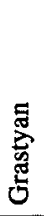 & 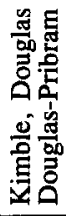 & 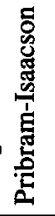 & $\begin{array}{l}\text { ㅁ } \\
\text { 응 } \\
\text { ஜ }\end{array}$ & $\frac{0}{\delta}$ & 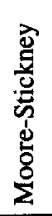 & 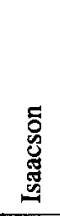 & 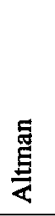 & 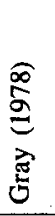 & 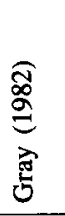 & 这 & 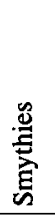 & $\begin{array}{l}\text { 莺 } \\
\text { J } \\
\end{array}$ & 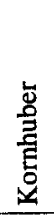 & 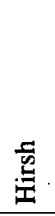 & 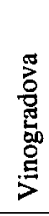 & 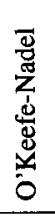 & $\frac{\Xi}{0}$ & 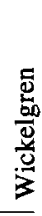 \\
\hline 1. Habituation to Novelty & $\mathrm{D}$ & D & D & $\mathbf{N}$ & D & $\mathrm{D}$ & $\mathrm{D}$ & D & $\mathrm{D}$ & -- & D & D & $\mathrm{D}$ & D & D & D & $\mathrm{D}$ & $\mathrm{D}$ & $\mathrm{D}$ & $\mathrm{D}$ \\
\hline 2. Acquisition & $\mathbf{N}$ & $\mathrm{N}$ & $\mathbf{N}$ & $\mathbf{N}$ & $\mathbf{N}$ & $\mathbf{N}$ & $\mathrm{D}$ & $\mathbf{N}$ & $\mathbf{N}$ & $\mathrm{N}$ & $\mathbf{N}$ & D & $\mathrm{D}$ & $\mathbf{N}$ & D & $\mathbf{N}$ & $\mathrm{D}$ & $\mathbf{N}$ & $\mathbf{N}$ & $\mathbf{N}$ \\
\hline 3. Extinction & D & D & D & D & D & D & $\mathbf{N}$ & D & D & $\mathrm{D}$ & $\mathrm{D}$ & -- & -- & $\mathrm{D}$ & -- & D & $-\cdot$ & $\mathrm{D}$ & $\mathbf{N}$ & $\mathrm{D}$ \\
\hline 4. Discrimination Reversal & D & D & D & D & D & $\mathrm{D}$ & $\mathrm{D}$ & D & D & $\mathrm{D}$ & $\mathrm{D}$ & -- & -- & D & - & D & -- & $\mathrm{N}$ & D & D \\
\hline 5. Spontaneous Alternation & D & $\mathrm{D}$ & D & $\mathbf{N}$ & $\mathrm{D}$ & -- & $\mathrm{D}$ & D & D & $\mathrm{D}$ & $\mathrm{D}$ & $\mathrm{D}$ & $\mathbf{N}$ & D & $\mathbf{N}$ & D & $\mathrm{D}$ & D & D & $\mathrm{D}$ \\
\hline 6. Latent Inhibition & D & $\mathrm{D}$ & D & $\mathbf{N}$ & $\mathrm{D}$ & $\mathrm{D}$ & $\mathrm{D}$ & $\mathbf{N}$ & $\mathbf{N}$ & $\mathbf{N}$ & D & -- & -- & $\mathrm{D}$ & -- & $\mathrm{D}$ & -- & $\mathrm{D}$ & $\mathbf{N}$ & $\mathrm{D}$ \\
\hline 7. Blocking & D & $\mathrm{D}$ & $\mathbf{N}$ & $\mathbf{N}$ & D & D & $\mathrm{D}$ & $\mathbf{N}$ & $\mathbf{N}$ & $\mathbf{N}$ & D & -- & -- & $\mathrm{D}$ & -- & $\mathrm{D}$ & -- & $\mathbf{N}$ & $\mathrm{N}$ & $\mathrm{D}$ \\
\hline 8. Overshadowing & D & D & D & D & D & D & $\mathrm{D}$ & $\mathbf{N}$ & $\mathbf{N}$ & $\mathbf{N}$ & D & -- & -- & $\mathbf{N}$ & -- & D & -- & $\mathbf{N}$ & $N$ & D \\
\hline 9. Conditioned Inhibition & $\mathbf{N}$ & $\mathbf{N}$ & D & $\mathbf{N}$ & $\mathbf{N}$ & $\mathbf{N}$ & $\mathbf{N}$ & D & $\mathrm{D}$ & $\mathbf{N}$ & $\mathrm{N}$ & $\mathrm{D}$ & $\mathrm{D}$ & $\mathbf{N}$ & D & $\mathbf{N}$ & D & $\mathbf{N}$ & $\mathbf{N}$ & $\mathbf{N}$ \\
\hline 10. Passive Avoidance & D & $\mathbf{N}$ & D & $\mathrm{D}$ & D & -- & $\mathrm{N}$ & D & D & $\mathrm{D}$ & D & $\mathrm{D}$ & D & $\mathrm{D}$ & $\mathrm{D}$ & D & $\mathrm{D}$ & D & $\mathbf{N}$ & D \\
\hline 11. Maze Learning & D & $\mathrm{D}$ & D & $\mathbf{N}$ & $\mathrm{D}$ & -- & $\mathrm{D}$ & D & $\mathrm{D}$ & $\mathrm{D}$ & $\mathrm{D}$ & $\mathrm{D}$ & $\mathrm{D}$ & $\mathrm{D}$ & $\mathrm{D}$ & D & $\mathrm{D}$ & D & D & D \\
\hline 12. Latent Learning & $\mathbf{N}$ & $\mathbf{N}$ & $\mathbf{N}$ & $\mathbf{N}$ & $\mathbf{N}$ & - & $\mathbf{N}$ & $\mathbf{N}$ & $\mathbf{N}$ & $\mathbf{N}$ & $\mathbf{N}$ & $\mathrm{D}$ & $\mathrm{D}$ & $\mathrm{D}$ & $\mathrm{D}$ & D & $\mathrm{D}$ & D & $\mathbf{N}$ & $\mathrm{D}$ \\
\hline 13. Retrograde Memory & D & $\mathbf{N}$ & $\mathbf{N}$ & $\mathbf{N}$ & $\mathbf{N}$ & -- & $\mathrm{N}$ & $\mathbf{N}$ & $\mathbf{N}$ & $\mathrm{N}$ & $\mathbf{N}$ & $\mathrm{D}$ & $\mathrm{D}$ & $\mathbf{N}$ & $\mathbf{N}$ & $\mathrm{D}$ & $\mathrm{N}$ & D & $\mathrm{N}$ & D \\
\hline 14. Working Memory Procedures & D & D & $\mathbf{N}$ & $\mathrm{N}$ & $\mathrm{N}$ & -. & $\mathrm{N}$ & $\mathrm{N}$ & $\mathrm{N}$ & D & D & D & $\mathrm{N}$ & D & $\mathrm{N}$ & D & D & D & D & D \\
\hline
\end{tabular}

Note $-D=$ deficit, $N=$ no deficit, $\cdots=$ no prediction. 
(5) Mackintosh's (1975) attentional theory, used by Moore and Stickney (1980); (6) Honig's (1978) and Olton's (1978) working memory concepts, used by Olton et al. (1979); and (7) Miller's (1956) chunk concept, used by Wickelgren (1979). Another aspect presented by only some of the models is the operation the hippocampus is supposed to carry out as a "computing device": (1) registration of the simultaneous presentation of a stimulus and nonreinforcement (Douglas, 1972); (2) "fast time" computations (Pribram \& Isaacson, 1975); (3) "efference copying" (Moore, 1979); or (4) comparisons (Adey, 1966; Gray, 1982; Kornhuber, 1973; Smythies, 1966; Vinogradova, 1975).

The attribution of a unitary psychological function to the hippocampus implies the identification of one localized area in the brain with complex psychological activities. Such an approach presents several methodological problems: (1) There are no grounds for assuming that "non-spatial concepts of psychology can be superimposed to the spatial construction of the brain" (Luria, 1966b, p. 36). This problem might be attenuated if it is considered that theorists aim to a convergence between psychological and physiological theoretical constructs. For instance, behavioral effects of hippocampal lesions have been used as evidence to support theoretical differences between short- and long-term memory (Iversen, 1976). (2) Any change in the current psychological theories affects what it considers to be the function of the structure. (3) Even though the hippocampus is presumed to be a functional homogeneous structure, hippocampal subdivisions can be differentially involved in behavior (e.g. , Buzsaki, Bors, Nagy, \& Eidelberg, 1982; Rickert, Lorden, Dawson, \& Smyly, 1981). (4) The same psychological function can be affected after lesions of different brain regions; for instance, deficits in extinction, spontaneous alternation, spatial learning, and discrimination reversal appear after neostriatal lesions (Oberg \& Divac, 1979), and deficits in blocking have been found after lesions of the mammilary bodies (Rickert et al., 1981). Also, deficits in spatial learning appear after lesions of the frontal cortex (Kolb, Pittman, Sutherland, \& Wishaw, 1982) or olfactory bulbs (Hall \& Macrides, 1983). (5) Lesions of discrete areas lead mostly to the loss of many psychological functions, and, as Jarrard (1973) observed, even if most of the theories of the hippocampus consider only a unitary process, the data suggest that several different behavioral processes may be affected by hippocampal lesion.

Conceptualizing the hippocampus as a "computational device" implies that psychological processes are distributed among different regions of the brain, and that each region performs a separate function, such as analysis, synthesis, comparisons of incoming information with anticipated results, etc. Luria (1966a) has called this approach "system localization" as opposed to the "function localization" considered before. The functions of different structures of the brain may change during certain psychological processes and may be reorganized after brain le- sions. Thus, the brain would be regarded as a system of interconnected information processing units, performing computations (analysis, synthesis, comparisons, storage, detections, encoding, etc.) on the representations of different events (stimuli, reponses, internal states, etc.). According to the theories of Adey (1966), Smythies (1966), Kornhuber (1973), Vinogradova (1975), O'Keefe and Nadel (1978), and Gray (1982), one computation carried out by the hippocampus is to compare stored information with incoming information. Information represented in the hippocampal formation has been identified as related to space (Best \& Rank, 1982; McNaughton, Barnes, \& O'Keefe, 1983), novelty (Vinogradova, 1975), images of conditioned responses (Berger, Rinaldi, Weisz, \& Thompson, 1983), and movement (Vanderwolf \& Robinson, 1981).

The following problems of using lesion data to validate psychological theories should also be considered: (1) Uncertainty about the boundaries of the lesions, such as secondary and circulatory disturbances-Schoenfeld and Hamilton (1977) have enumerated these changes as: necrosis, regeneration and sprouting, denervation supersensitivity, alteration of neurochemical pools, and diaschisis. Bar, Gispen, and Isaacson (1980) have evaluated the changes after hippocampal lesions, showing that the secondary changes involve the nucleus accumbens and the caudate. (2) Logical fallacy when a "positive" function is deduced from the "negative" characteristic of a symptom-All that an experiment can tell us is what the brain can do after the damage in certain specific conditions. (3) Restoration of function after brain damage-In the case of the hippocampus, its lesion produces loss of the established memory about place discrimination, but the discrimination can be reacquired with further training (Becker et al., 1981). The possibility that functions performed primarily by the hippocampus could be, after its damage, undertaken by other areas opens a plausible defense for models predicting more effects than those actually found after the lesion. For instance, the only wrong prediction made by Hirsh's and Wickelgren's models (see Table 1) is impaired latent learning, but the additional assumption that this phenomenon is mediated by areas other than the hippocampus after the lesion opens the way to saving the validity of these models.

The preceding discussion suggests that it would be more productive to define the hippocampus as a computational device than to attribute a unitary psychological function to it. However, despite the shortcomings inherent in attributing a unitary psychological function to the hippocampus, as most of the theories propose, some of the models can be used to summarize aspects of the sequelae of the hippocampal damage: attentional deficits, expressed as "tuning out" irrelevant stimuli, spatial learning deficits, working memory deficits, etc.

Also, from the preceding, it is suggested that the lesion literature, even if only able to generate "weak" conclusions about the role of the hippocampus in the impaired 
functions, can produce "strong" conclusions about the psychological consequences of the lesions.

It is suggested, therefore, that the function of the hippocampus is more likely to be a "computationalrepresentational activity" rather than a "psychological function." Knowledge of this activity involves the uncovering of what information is represented and processed by this structure.

\section{REFERENCES}

ADEY, W. R. (1966). Neurophysiological correlates of information transaction and storage in brain tissue. In E. Stellar \& J. M. Sprague (Eds.), Progress in physiological psychology (Vol. 1) New York: Academic Press.

Altman, J. R., Brunner, R. L., \& Bayer, S. A. (1973). The hippocampus and behavioral maturation. Behavioral Biology, 8, 557-596.

BAR, P. R., GISPEN, W. H., \& IsAacson, R. L. (1980). Behavioral and regional neurochemical sequelae of hippocampal destruction in the rat. Pharmacology, Biochemistry and Behavior, 14, 305-312.

BeCKer, J. T., \& OLTON, D. S. (1980). Object discrimination by rats: The role of frontal and hippocampal systems in retention and reversal. Physiology \& Behavior, 24, 33-38.

Becker, J. T., Olton, D. S., Anderson, C. A., \& Breitinger, E. R. P. (1981). Cognitive mapping in rats: The role of the hippocampal and frontal systems in retention and reversal. Behavioral Brain Research, 3, 1-22.

BENNET, T. L. (1971). Hippocampal theta activity and behavior-A review. Communications in Behavioral Biology, 6, 37-38.

Berger, T. W., Alger, B., \& Thompson, R. F. (1978). Neuronal substrate of classical conditioning in the hippocampus. Science, 192, 483-485.

Berger, T. W., \& ORR, W. B. (1983). Hippocampectomy selectively disrupts discrimination reversal conditioning of the rabbit nictitating membrane response. Behavioral Brain Research, 8, 49-68.

Berger, T. W., Rinaldi, P., Weisz, D., \& Thompson, R. F. (1983). Single-unit analysis of different hippocampal cell types during classical conditioning of rabbit nictitating membrane response. Journal of Neurophysiology, 50, 1197-1219.

BEST, P. J., \& RANK, J. B. (1982). Reliability of the relationships between hippocampal unit activity and sensory-behavioral events in the rat. Experimental Neurology, 75, 652-664.

Buzsaki, G., Bors, L., Nagy, F., \& Eidelberg, E. (1982). Spatial mapping, working memory, and the fimbria-fornix system. Journal of Comparative and Physiological Psychology, 96,, 26-34.

Douglas, R. (1967). The hippocampus and behavior. Psychological Bulletin, 67, 416-442.

Douglas, R. (1972). Pavlovian conditioning and the brain. In R. A. Boakes \& M. S. Halliday (Eds.), Inhibition and learning. London: Academic Press.

Douglas, R., \& IsAacson, R. L. (1964). Hippocampal lesions and activity. Psychonomic Science, 1, 187-188.

Douglas, R., \& Pribram, K. H. (1966). Learning and limbic lesions. Neuropsychologia, 4, 197-220.

GaFFAN, D. (1972). Loss of recognition memory in rats with lesions of the fornix. Neuropsychologia, 10, 327-341.

GAFFAN, D. (1973). Inhibitory gradients and behavioral contact in rats with lesions of the fornix. Physiology \& Behavior, 11, 215-220.

Grastyan, E., Lissak, K., Madarasz, I., \& Donhoffer, H. (1959). Hippocampal electrical activity during the development of conditioned reflexes. Electroencephalography and Clinical Neurophysiology, 11, 409-430.

GraY, J. A. (1982). Multiple book review of the neuropsychology of anxiety: An inquiry into the functions of the septo-hippocampal system. Behavioral and Brain Sciences, 5, 469-534.

Gray, J. A., Feldon, J., Rawlins, J. N. P., Owen, S., \& McNaughTON, N. (1978). The role of the septo-hippocampal system and its noradrenergic afferents in behavioral responses to non-reward. In Functions of the septo-hippocampal system. Ciba Foundation Symposium, Amsterdam.

Gray, J. A., Rawlins, J. N. P. \& Feldon, J. (1979). Brain mechanisms in the inhibition of behavior. In A. Dickinson and R. A. Boakes (Eds.), Mechanisms of learning and motivation. Hillsdale, NJ: Erlbaum.

Green, J. D., \& ARDuini, A. A. (1954). Hippocampal electrical activity in arousal. Journal of Neurophysiology, 17, 533-557.

HALL, R. D., \& MaRCIDES, F. (1983). Olfactory bulbectomy impairs the rat's radial-maze behavior. Physiology \& Behavior, 30, 797-803.

Hess, W. R. (1949). Das Zwischenhirn. Basel: Schwabe.

HIRSH, R. (1974). The hippocampus and contextual retrieval of information from memory: A theory. Behavioral Biology, 12, 421-444.

HIRSH, R. (1980). The hippocampus, conditional operations and cognition. Physiological Psychology, 8, 1975-182.

HonIG, W. K. (1978). Studies of working memory in the pidgeon. In S. H. Hulse, H. Fowler, \& W. K. Honig (Eds.), Cognitive aspects of animal behavior. Hillsdale, NJ: Erlbaum.

IsAaCsON, R. L. (1972). Neural systems of the limbic brain and behavioral inhibition. In R. A. Boakes \& M. S. Halliday (Eds.), Inhibition and learning. London: Academic Press.

IVERSON, S. D. (1976). Do hippocampal lesions produce amnesia in animals? In C. C. Pfeiffer \& J. R. Smythies (Eds.), International review of neurobiology. New York: Academic Press.

JARRARD, L. E. (1973). The hippocampus and motivation. Psychological Bulletin, 79, 1-12.

JARRARD, L. E., ISAACSON, R. L., \& WICKELGREN, W. O. (1964). Effects of hippocampal ablation and intertrial interval on acquisition and extinction of a runway response. Journal of Comparative and Physiological Psychology, 57, 442-445.

KimbeL, D. P. (1963). The effects of bilateral hippocampal lesions in rats. Journal of Comparative and Physiological Psychology, 56, 273-283.

Kimble, D. P. (1968). Hippocampus and internal inhibition. Psychological Bulletin, 70, 285-295.

KimBle, D. P. \& BREMILLER, R. (1981). Latent learning in hippocampallesioned rats. Physiology \& Behavior, 26, 1055-1059.

Kimble, D. P., Kirby, R. J., \& STEIN, D. G. (1966). Response perseveration interpretation of passive avoidance deficits in hippocampectomized rats. Journal of Comparative and Physiological Psychology, 61, 141-144.

Kolb, B., Pittman, K., Sutherland, R. J., \& Whishaw, I. Q. (1982) Dissociation of the contribution of the prefrontal cortex and dorsomedial thalamic nucleus to spatially guided behavior in the rat. $\mathrm{Be}$ havioral Brain Research, 6, 365-387.

KonorsKI, J. (1948). Conditioned reflexes and neuron organization. Cambridge: Cambridge University Press.

KoRnhUber, H. H. (1973). Neural control of input into long term memory: Limbic system and amnestic syndrome in man. In H. P. Zippel (Ed.), Memory and transfer of information. New York: Plenum Press.

Krechevsky, I. (1932). "Hypothesis" in rats. Psychological Review, 39, 516-533.

LURIA, A. R. (1966a). The frontal lobes and the regulation of behavior. In K. H. Pribram \& A. R. Luria (Eds.), Psychobiology of the frontal lobes. New York: Academic Press.

LURIA, A. R. (1966b). Human brain and psychological processes. New York and London: Harper and Row.

Mackintosh, N. J. (1975). A theory of attention: Variations in the associability of stimuli with reinforcement. Psychological Review, 82, 276-298.

McFarland, D. J., Kostas, J., \& Drew, W. G. (1978). Dorsal hippocampal lesions: Effects of preconditioning CS exposure on flavor aversion. Behavioral Biology, 22, 398-404

McNaughton, B. L., Barnes, C. A., \& O'Keefe, J. (1983). The contributions of position, direction, and velocity to single unit activity in the hippocampus of freely-moving rats. Experimental Brain Research, 52, 41-49. 
Means, L. W., Walker, D. W., \& Isaacson, R. L. (1970). Facilitation of single alternation go/no-go acquisition following hippocampectomy in the rat. Journal of Comparative and Physiological Psychology, 72, 278-285.

Micco, D. J., \& SchwarTz, M. (1971). Effects of hippocampal lesions upon the development of Pavlovian internal inhibiton in rats. Journal of Comparative and Physiological Psychology, 76, 371-377.

MiLleR, G. A. (1956). The magical number 7, plus or minus two: Some limits on our capacity for processing information. Psychological Review, 63, 81-97.

MOORE, J. W. (1979). Brain processes and conditioning. In A. Dickinson \& R. A. Boakes (Eds.), Mechanisms of learning and behavior. Hillsdale, NJ: Erlbaum.

MOORE, J. W. , \& STICKNEY, K. J. (1982). Goal tracking in attentionalassociative networks. Spatial learning and the hippocampus. Physioplications for conditioning. Physiological Psychology, 8, 207-217.

MOORE, J. W. \& STICKNEY, K. J. (1982). Goal tracking in attentionalassociative networks: Spatial learning and the hippocampus. Physiological Psychology, 10, 202-208.

NADEL, L., \& MaCDonald, L. (1980). Hippocampus: cognitive map or working memory. Behavioral and Neural Biology, 29, 405-409.

Nixi, H. (1965). The effect of hippocampal ablation on the inhibitory control of operant behaviour in the rat. Japanese Psychological Research, 7, 126-137.

OADES, R. D. (1981). Impairments in search behavior in rats after haloperidol treatment, hippocampal or cortical damage suggest a mesocorticolimbic role in cognition. Biological Psychology, 12, 77-85.

OberG, R. G. E., \& Divac, I. (1979). "Cognitive" functions of the neostriatum. In J. Divac \& R. G. E. Oberg (Eds.), The neostriatum. Oxford: Pergamon Press.

O'Keefe, J. (1979). A review of the hippocampal place cells. Progress in Neurobiology, 31, 419-439.

O'KeEFE, J., \& NADEL, L. (1978). The hippocampus as cognitive map. Oxford: Claredon University Press.

O'Keefe, J., NADEL, L., \& WiLNER, J. (1979). Tuning out irrelevancy? Comments on Solomon's temporal mapping view of the hippocampus. Psychological Bulletin, 86, 1280-1289.

OltoN, D. S. (1972). Behavioral and neuroanatomical differentiation of response-suppression and response-shift mechanisms in the rat. Journal of Comparative and Physiological Psychology, 78, 450-456.

Olton, D. S. (1978). Characteristics of spatial memory. In S. H. Hulse, H. Fowler, \& W. K. Honig (Eds.), Cognitive aspects of animal behavior. Hillsdale, $\mathrm{NJ}$; Erlbaum.

Olton, D. S., Becker, J. T., \& Handelmann, E. (1979). Hippocampus, space and memory. Behavioral and Brain Sciences, 2, 313-366.

Pavlov, I. (1927). Conditioned reflexes: An investigation of the physiological activity of the cerebral cortex. New York: Oxford University Press.

Pribram, K. H., \& IsaAcson, R. L. (1975). Summary. In R. L. Isaacson \& K. H. Pribram (Eds.), The hippocampus. New York: Plenum Press.

Rickert, E. J., Bennet, T. L., LANe, P., \& French, J. (1978). Hippocampectomy and the attenuation of blocking. Behavioral Biology, 22, $147-160$.

Rickert, E. J., Lorden, J. F., Dawson, R., \& SMYly, E. (1981). Limbic lesions and the blocking effect. Physiology \& Behavior, 26, 601-606.

Rickert, E. J., Lorden, J. F., Dawson, R., Smyly, E., \& CallaHAN, M. F. (1979). Stimulus processing and stimulus selection in rats with hippocampal lesions. Behavioral and Neural Biology, 27, 454-465.

SARA, S. J. (1981). Memory deficits in rats with hippocampal or cortical lesions. Behavioral and Neural Biology, 32, 504-509.

Schmajux, N. A., SpEar, N. E., \& ISAaCson, R. L. (1983). Absence of overshadowing in rats with hippocampal lesions. Physiological Psychology, 11, 59-62.

Schmaltz, L. W., \& IsaACSON, R. L. (1967). Effect of bilateral hippocampal destruction on the acquisition and extinction of an operant response. Physiology \& Behavior, 2, 291-298.

Schmaltz, L. W., \& Theios, J. (1972). Acquisition and extinction of a classically conditioned response in hippocampectomized rabbits (Oryctolagus cuniculus). Journal of Comparative and Physiological Psychology, 79, 328-333.

Schoenfeld, T. A., \& Hamilton, L. W. (1977). Secondary brain changes following lesion: A new paradigm for lesion experimentation. Physiology and Behavior, 18, 951-967.

SMYthres, J. R. (1966). Brain mechanisms and behavior. New York: Academic Press.

Sokolov, E. N. (1960). Neuronal models and the orienting reflex. In M. A. B. Brazier (Ed.), The central nervous system and behavior. New York: Macy Foundation.

Solomon, P. R. (1977). Role of the hippocampus in blocking and conditioned inhibition of rabbit's nictitating membrane response. Journal of Comparative and Physiological Psychology, 91, 407-417.

SoLOMON, P. R. (1979). Temporal versus spatial information processing theories of the hippocampal function. Psychological Bulletin, 86, 1272-1279.

Solomon, P. R. (1980). A time and a place for everything? Temporal processing views of hippocampal function with special reference to attention. Physiological Psychology, 8, 254-261.

Solomon, P. R., \& MOORE, J. W. (1975). Latent inhibition and stimulus generalization of the classically conditioned nictitating membrane response in rabbits (Oryctolagus cuniculus) following dorsal hippocampal ablation. Jourral of Comparative and Physiological Psychology, 89, 1192-1203.

SPEAR, N. E. (1981). Extending the domain of memory retrieval. In R. R. Miller \& N. E. Spear (Eds.), Information processing in animals: Memory mechanims. Hillsdale, NJ: Erlbaum.

StANTON, M., \& AMSEL, A. (1980). Adjustment to reward reduction (but no negative contrast) in rats 11,14 and 16 days of age. Journal of Comparative and Physiological Psychology, 95, 446-458.

Sutherland, N. S., \& Mackintosh, N. J.(1971). Mechanisms of animal discrimination learning. New York: Academic Press.

Swanson, L. W., TeYler, T. J., \& Thompson, R. F. (1981). Hippocampal long-term potentiation mechanisms and implications for memory. Neurosciences Research Program Bulletin, 20, 612-767.

Thomas, G. J., Brito, G. N., Stein, D. P., \& Berko, J. K. (1982). Memory and the septohippocampal connections in rats. Physiological Psychology, 96, 339-347.

Tolman, E. C. (1932). Purposive behavior in animals and men. New York: Appleton-Century-Crofts.

VANDERWOLF, C. H., \& RoBINSON, T. E. (1981). Reticulo-cortical activity and behavior: A critique of the arousal theory and a new synthesis. Behavioral and Brain Sciences, 4, 459-514.

VinoGradova, O. S. (1975). Functional organization of the limbic system in the process of registration of information: Facts and hypothesis. In R. L. Isaacson \& K. H. Pribram (Eds.), The hippocampus. New York: Plenum Press.

WICKELGREN, W. A. (1979). Chunking and consolidation: A theoretical synthesis of semantic networks, configuring in conditioning, S-R versus cognitive learning, normal forgetting, the amnestic syndrome and the hippocampal arousal system. Psychological Review, 86, 44-60.

WinOCUR, G., \& OLDS, J. (1978). Effects of context manipulation on memory and reversal learning in rats with hippocampal lesions. Journal of Comparative and Physiological Psychology, 92, 312-321.

(Manuscript received July 11,1983 ; revision accepted for publication August 13, 1984.) 